Review

\title{
Methanol-to-propylene process: Perspective of the most important catalysts and their behavior
}

\author{
M. Khanmohammadi a,*, Sh. Amani a, A. Bagheri Garmarudi a, A. Niaei ${ }^{b}$ \\ a Department of Chemistry, Faculty of Science, Imam Khomeini International University, Qazvin, Iran \\ b Department of Chemical Engineering and Applied Chemistry, University of Tabriz, 51666-16471, Tabriz, Iran
}

A R T I C L E I N F O

Article history:

Received 5 October 2015

Accepted 16 December 2015

Published 5 March 2016

Keywords:

Methanol-to-propylene process

ZSM-5 zeolite

Catalysis

\begin{abstract}
A B S T R A C T
The methanol-to-propylene (MTP) process is a route of methanol conversion to hydrocarbons, which is in high demand because of limited oil resources. The present paper discusses the effect of catalyst structure on the MTP process conditions, and the role of different zeolite factors, such as acidity, crystal size, mesoporosity, and topology, on the activity and selectivity of the MTP reaction.
\end{abstract}

(C) 2016, Dalian Institute of Chemical Physics, Chinese Academy of Sciences. Published by Elsevier B.V. All rights reserved.

\section{Introduction}

Propylene is one of the key building blocks of petrochemicals used as a feedstock for a variety of polymer and chemical intermediates, such as polypropylene, acrylonitrile, propylene oxide, and many other commodity chemicals that are consumed as substitutes for non-plastic materials (e.g., paper, steel, and wood). Recent developments in the production of propylene derivatives, especially polypropylene, which requires a major fraction (about 60\%) of the total propylene, have led to growing global demand for propylene at an annual rate of approximately 5\%-6\% [1,2]. Fluid catalytic cracking and steam cracking are two major commercial methods of propylene production, and both are dependent on crude oil resources [3]. Considering the increasing consumption of propylene and the expected shortage of petroleum resources in the future, the petrochemical industry is presently facing a crisis in propylene availability, and the lack of novel processes for the production of propylene is becoming clear [4]. The metha- nol-to-olefins (MTO) process developed by UOP/Norsk Hydro [5] and the methanol-to-propylene (MTP) process developed by Lurgi [6] are promising alternative approaches for the production of propylene. Because methanol can be easily produced from natural gas, coal, and biomass with lower prices and more availability than crude oil, these two routes have attracted significant attention [7-10]. The Dalian Institute of Chemical Physics, Chinese Academy of Sciences, has developed an MTO technology, known as dimethyl ether or methanol-to-olefin, which has been used in the world's first coal-to-olefin plant $[11,12]$. The MTO process uses small-pore silicoaluminophosphate molecular sieves (SAPO-34) as catalysts, and the main product is ethylene [13,14]. Lurgi's MTP process has optimized the propylene yield in the MTO process using MFI-type framework high silica zeolite catalysts (H-ZSM-5), and the high propylene to ethylene ratio $(\mathrm{P} / \mathrm{E})$ was a criterion, enabling higher selectivity for propylene in the recirculation process [6]. In the MTO process, methanol is first dehydrated to dimethyl ether to form an equilibrium mixture of methanol, dimethyl ether, and

* Corresponding author. Tel/Fax: +98-28-3378 0040; E-mail: m.khanmohammadi@sci.ikiu.ac.ir DOI: 10.1016/S1872-2067(15)61031-2 | http://www.sciencedirect.com/science/journal/18722067 | Chin. J. Catal., Vol. 37, No. 3, March 2016 


\section{$2 \mathrm{CH}_{3} \mathrm{OH} \rightleftharpoons \mathrm{CH}_{3} \mathrm{OCH}_{3} \longrightarrow$ Light olefins $\downarrow$ \\ Heavy olefins $+n /$ iso-paraffins + aromatics + naphthenes}

Scheme 1. Reaction path of methanol during the MTO process [14].

water. The equilibrium mixture is then converted to light olefins, which can further react to form paraffin, aromatics, naphthenes, and higher olefins via hydrogen transfer, alkylation, or polycondensation (Scheme 1) $[1,14]$.

In the MTP process developed by Lurgi, apart from propylene as main product, ethylene and other olefins, also fuel gas, gasoline range hydrocarbons, and liquefied petroleum gas can be produced, depending on the reaction conditions and operating parameters used [6]. The important key step in the effective conversion of MTP is to control the reaction during olefin formation, where the acidity of the catalyst plays an essential role. Various acidic catalysts, mostly zeolites, have been evaluated for methanol conversion to light olefins [15-18]. Zeolites (microporous crystalline aluminosilicates) are widely used in petrochemical and fine chemical syntheses because of their strong acidic sites within the uniform micropores, as size- and shape-selective catalysts $[7,8]$. These frameworks are three-dimensional networks composed of $\mathrm{TO}_{4}$ tetrahedra $(\mathrm{T}=$ $\mathrm{Si}, \mathrm{Al}$ ) linked by oxygen ions. When some of the $\mathrm{Si}_{4}{ }^{+}$ions in the $\mathrm{SiO}_{4}$ tetrahedra are replaced by $\mathrm{Al}_{3}{ }^{+}$ions, an excess negative charge is generated. Mobile alkali metal ions are considered as a compensating source of positive charge, which can be exchanged with other cations (nonframework cations). Numerous reports have been presented supporting Lurgi's process, indicating aluminosilicate $\mathrm{H}-\mathrm{ZSM}-5$ as the appropriate candidate catalyst for the MTP reaction [1-3,5-10]. This topology has a medium size pore system with two channels, both including 10-ring channels. Straight channels (5.1-5.5 ̊) are intersected by zigzag channels (5.3-5.6 ̊), creating a threedimensional network [19]. In the MTP process developed by Lurgi, at least $35 \%$ of one-pass propylene selectivity has been achieved at atmospheric or nearly atmospheric pressure at a reaction temperature range of $350-500{ }^{\circ} \mathrm{C}$ using a fixed bed reactor and ZSM-5 (MFI) zeolite catalyst [20,21]. Commercial use of the MTP process involves fixed-bed reactors, and numerous patents have discussed their design, obtaining higher selectivity by recycling the formed olefins, after propylene extraction, into the reactor [22-26]. However, propylene selectivity and the $\mathrm{P} / \mathrm{E}$ ratio are still low, and the improvement of one-pass selectivity to propylene has been regarded as the major challenge and emphasis of current research on the MTP reaction. Among all of the parameters, the catalyst plays effective and important roles in determining the process features and efficiency [16]. To develop a commercial catalyst for the MTP reaction, stable and high methanol conversion and propylene selectivity are critical [27]. Physical and chemical properties of ZSM-5 zeolite (e.g., channel structure, total acidity, and crystal size) and operating conditions affect the selectivity for propylene [28-30].

The present contribution reviews the effect of catalyst structure on the MTP process conditions and yield. Catalysts are classified into two categories: ZSM-5 and non-ZSM-5 with other topologies, and recent advances regarding the improvements in utilizing catalysts with higher propylene selectivity and more stability in the MTP process are investigated. The roles of different factors such as acidity, crystal size, mesoporosity, and topology of zeolite on the activity and selectivity of the catalyst toward the MTP reaction are studied. This review covers articles published within the past decade reporting different methods of improving the propylene selectivity and catalyst stability in the MTP reaction.

\section{Mechanism and pathways of the reaction}

Due to the complexity in product distribution and the difficulty in reaction intermediate identification, understanding the MTP reaction mechanism is still challenging [31]. To date, more than 20 distinct mechanisms have been proposed to elucidate the MTO reaction and how $\mathrm{C}-\mathrm{C}$ forms from $\mathrm{C} 1$ through various processes, which can be broadly divided into direct (consecutive) and indirect (parallel) processes. Some of these mechanisms can be grouped into classes based on whether the key intermediates are oxonium ylides, carbenes, carbocations, free radicals or surface-bound alkoxy species $[32,33]$. Currently, the direct $\mathrm{C}-\mathrm{C}$ coupling mechanism is an unfavorable route because it operates at a rate near zero; an indirect route is widely accepted [33].

The basic feature of this indirect route is that the organic reaction centers act as scaffolds for producing light olefins (i.e., ethene and propene) within the pores of molecular sieves to avoid high-energy intermediates required by the direct mechanisms [32]. An indirect reaction cycle known as the hydrocarbon pool mechanism has been adopted as the dominant reaction mechanism and is presented in Scheme 2. This mechanism consists of a cycle of reactions in which methanol successively reacts with the organic hydrocarbon pool via methylation leading to $\mathrm{C}-\mathrm{C}$ bond formation. Subsequently, the cracking of higher olefins through an autocatalytic reaction [14] produces light olefins such as ethylene and propene, which regenerate the initial hydrocarbon pool species and completes the catalytic cycle [14,34-37].

Pathway of successive methylation/cracking of methanol and reaction intermediates have been demonstrated by nuclear magnetic resonance (NMR) studies [38]. Several studies have shown that alkylaromatic intermediates (methylbenzenes) may form in the hydrocarbon pool $[39,40]$. The nature and concentration of alkylaromatic intermediates formed in the zeolite

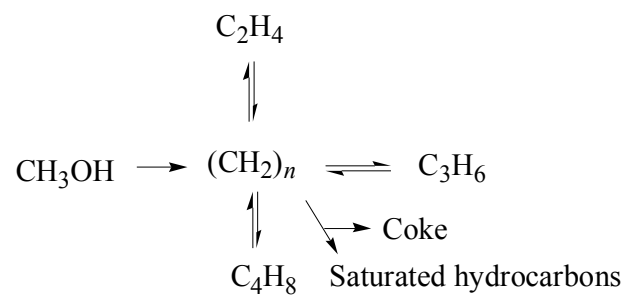

Scheme 2. Proposed hydrocarbon pool mechanism by Dahl et al. [36]. 
pores determine their product composition, as well as their deactivation rates during the process, and the catalytic mechanism has important differences from one topology to another [41]. For example, H-beta (BEA) with mutually perpendicular 12-ring channels (5.6 × 5.6 and $6.6 \times 6.7 \AA$ ) showed that heptamethylbenzenium cations are active intermediates in the MTO reaction [42]. H-SAPO-34 with 20-hedralcha-cages $(6.7 \AA$ in diameter and $10.0 \AA$ in height) interconnected by 8-ring windows $(3.8 \times 3.8 \AA)$ showed that hexamethylbenzene is a significant reaction intermediate [43]. Polymethylbenzenes (MBs) and especially three cyclopentenyl cations (1,3-dimethylcyclopentenyl, 1,2,3-trimethylcyclopentenyl and 1,3,4-trimethylcyclopentenyl) and a pentamethylbenzenium ion were identified by solid-state NMR spectroscopy in the MTO reaction at $300-400{ }^{\circ} \mathrm{C}[11,44]$.

MBs or other related cyclic species confined in the zeolite cage or channel intersection act as co-catalysts in the generation of olefins [11], and it has been proposed that MTP is an autocatalytic reaction. The initial reaction of small amounts of reactant enhances methanol conversion to products until the efficient production period is reached $[11,14,44]$. Recently, Bjørgen et al. [45] have introduced a dual-cycle reaction mechanism involving aromatic-based and alkene-based catalytic cycles as shown in Scheme 3. Their studies demonstrate that the mechanism of ethylene formation is distinct from the mechanism of propylene formation under the reported reaction conditions $[46,47]$. The aromatic-based cycle produces ethene and propene with equal selectivity, whereas the olefin-based cycle favors $\mathrm{C}_{3}{ }^{+}$olefins over ethene $[48,49]$. The olefin-based scheme was also proposed by $\mathrm{Wu}$ et al. [8] for propylene formation over a high silica ZSM-5 catalyst in a fixed-bed reactor in the MTP process.

In the case of MBs and their protonated substructures such as benzenium ions, there are two different aromatic-based routes for the operation of the hydrocarbon pool mechanism. The first one is side-chain methylation proposing the formation of light olefins via the elimination of alkyl chains that is generated by repeated methylation of aromatics. The second one is a paring approach in which ring contraction and expansion of a benzenium ion occurs, forming an alkyl chain and its subsequent splitting to produce light olefins [44]. Side-chain methylation and paring routes are shown in Scheme 4 [44].

\section{Coke formation on ZSM-5 catalyst}

ZSM-5 is an active catalyst, but coke formation is a problem that causes rapid deactivation [50-52]. Accumulation of coke deposits block the micropores of the catalyst and physically restricts the access of reactants towards the catalytic scaffold, stopping the release of the products. The deactivation rate and deactivating materials are different at different temperatures. At low temperatures $\left(270-300{ }^{\circ} \mathrm{C}\right)$, the initially formed unsaturated hydrocarbons from the methanol conversion in the pores react mainly with methanol to form larger unsaturated compounds by methylation and dehydrogenation reactions. Deactivation of H-ZSM-5 at these temperatures is benzene ring

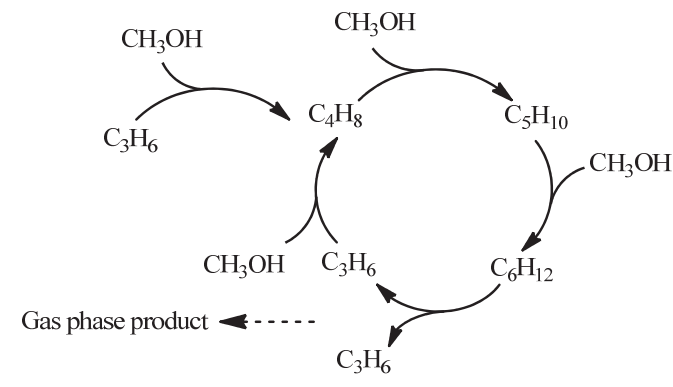

Olefin-based cycle

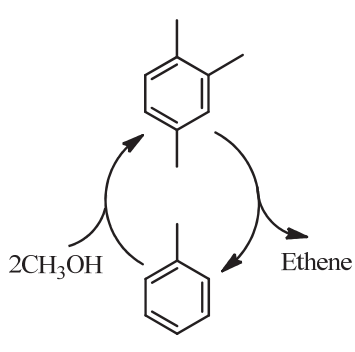

Aromatic-based cycle

Scheme 3. Proposed dual-cycle concept for the conversion of methanol over H-ZSM-5 [45].

Side-chain methylation route

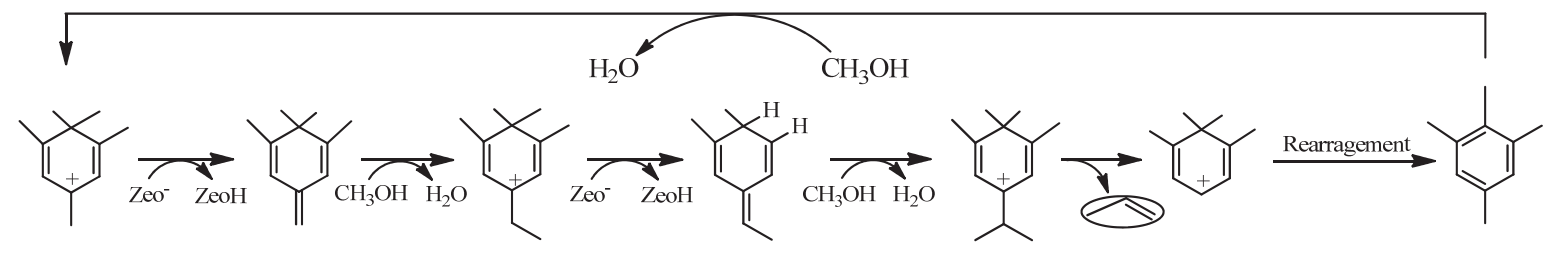

Paring route

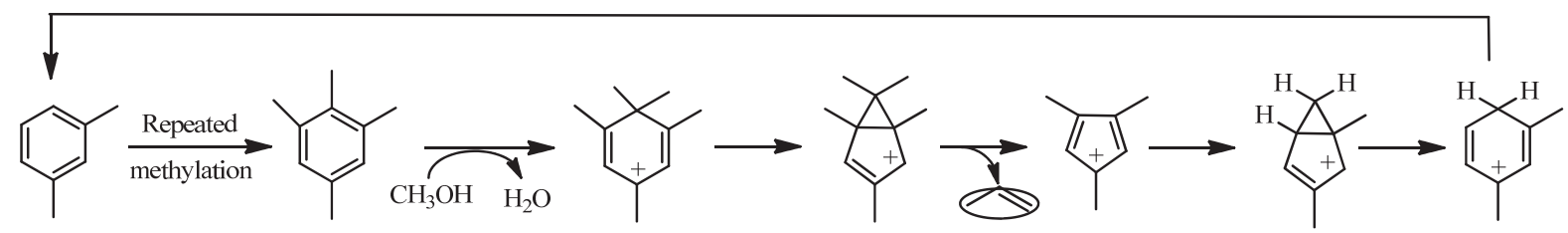

Scheme 4. Paring and side-chain methylation pathways for propylene formation over H-ZSM-5 [44]. 


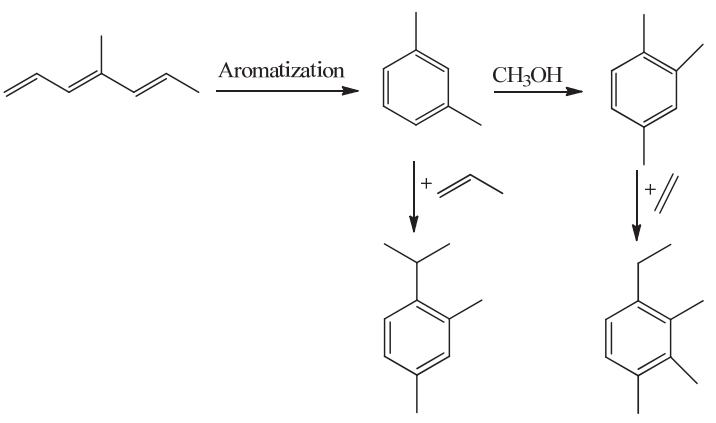

Scheme 5. Proposed mechanism of formation of retained molecules in the pores of zeolite $\mathrm{H}-\mathrm{ZSM}-5$ during methanol conversion at low temperatures $\left(270-300^{\circ} \mathrm{C}\right)[20]$.

alkylation with ethene and propene, which produces ethyl-trimethyl-benzene and isopropyl-dimethyl-benzene that block the pore system [20]. This reaction is shown schematically in Scheme 5. At higher temperatures $\left(300-400{ }^{\circ} \mathrm{C}\right)$, alkylation of benzene rings with olefins is reversible, reactivating the ZSM- 5 catalyst and increasing catalyst lifetime. At temperatures higher than $400{ }^{\circ} \mathrm{C}$, catalyst lifetime decreases and changes the mechanism of deactivation. The coke formation is intensified at temperatures higher than $400^{\circ} \mathrm{C}$.

Coke formation at higher than $400{ }^{\circ} \mathrm{C}$ can be related to the specific pore structure of H-ZSM-5 zeolite, restricting pore filling because the largest molecules, which can be formed in the cavities via alkylation of benzene rings with olefins, are instable against dealkylation. Coke formation on the surface of H-ZSM-5 crystallites is slow, initially on coke seeds from olefin coking (downstream before the methanol reaction zone). By further reacting coke with methanol for methylation and dehydrogenation, the catalyst is deactivated. Methane among the volatile compounds is indicative of this coking. The coke growth reaction over ZSM-5 in methanol conversion at $475{ }^{\circ} \mathrm{C}$ is shown schematically in Scheme 6.

Comparative investigation of methanol conversion over five different zeolite topologies, namely Y, ZSM-5, ZSM-58, EU-1, and BEA, at $475^{\circ} \mathrm{C}$ has shown that catalyst lifetime for H-ZSM- 5 is about 70 times longer than that of the other types (conversion of $123 \mathrm{~g}$ of methanol per gram of the catalyst for H-ZSM- 5 and less than $2 \mathrm{~g}$ for the other types) [20]. The stability of ZSM- 5 is the highest compared with those of ZSM-48, EU-1, and BEA topologies during the MTP reaction at $450{ }^{\circ} \mathrm{C}$, and the selectivity to propylene was the highest for EU-1. The deactivation rates during the MTP reaction increase in the order ZSM-5 $\leq$ BEA < EU-1 < ZSM-48 [15,20]. Therefore, the major catalysts proposed for the MTP reaction are based on H-ZSM-5 zeolite and, as mentioned above, coke is formed slower on the surface of its crystallites compared with the rates of other zeolite frameworks. ZSM-5 coking during the MTO reaction does not proceed in the pores, but on the crystallites surface via methylation and dehydrogenation by reaction with methanol [51]. As coke forms on the surface of the catalyst, particle size and particle density and the type of active sites on the crystallite surface influence the catalyst lifetime [20].

Coke formation and its composition are both influenced by zeolite acidity because coke compounds are strongly adsorbed

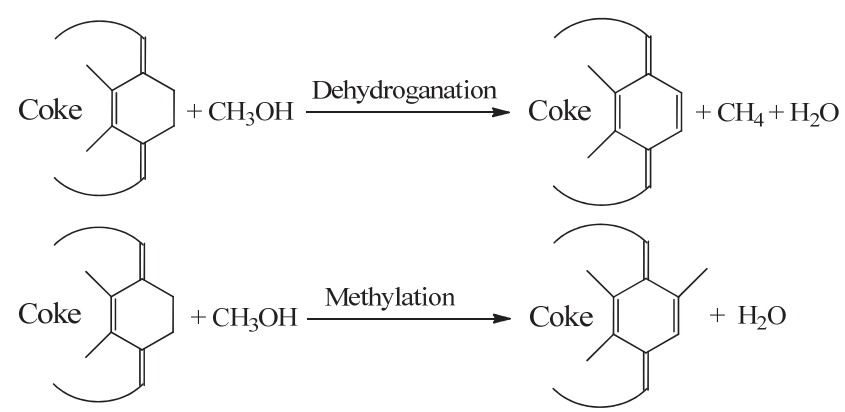

Scheme 6. Proposed coke growth reaction over the ZSM-5 in methanol conversion at $475^{\circ} \mathrm{C}$.

on Brønsted and Lewis acid sites and block pore entrances [53-55]. Topsøe et al. [56] first indicated the significant decrease in the concentration of acid sites during the catalyst deactivation period in methanol conversion over H-ZSM-5. The investigation of individual H-ZSM-5 crystals by varying the Brønsted acid site density in MTO conversion by using situ ultraviolet-visible (UV-Vis) and confocal fluorescence microscopy has demonstrated that the $\mathrm{Si} / \mathrm{Al}$ molar ratio, which reflects the acidity of catalyst, influences the deactivation characteristics. The results indicate that at low reaction temperatures, the Brønsted acid site density does not affect the chemical nature of the formed coke species. Although with increasing available acid sites, the formation of the coke compounds occurs faster, and the growth of methyl-substituted aromatic compounds into extended linear aromatic compounds is facilitated. Rising the reaction temperature causes the fast formation of larger aromatic species to occur, and larger graphite-like coke deposits are formed at the external surface of the catalysts, especially for the most acidic crystals, which leads to pore blockage. The coke growth process becomes less prominent as the Brønsted acid site density is decreased, such as a $\mathrm{Si} / \mathrm{Al}$ molar ratio higher than 17 . Thus, the rate of coke formation can be decreased by reducing the $\mathrm{Al}$ content. Kinetics studies have revealed that an increased Brønsted acid site density facilitates the evolution of larger coke species and enhances their formation rate [57].

Employing MFI zeolites with different degrees of mesoporosity in the methanol-to-hydrocarbon reaction has revealed that the main fraction of coke is formed on the external surface of the catalyst, which is unlike that for microporous zeolites where coke is strongly deposited inside the micropores [16]. Thus, the application of mesoporous zeolite structures could prevent coke formation inside the pores. Additionally, to improve the olefin selectivity, aromatic formation that leads to coke formation via methylation and dehydrogenation can be avoided by dilution with $\mathrm{H}_{2} \mathrm{O}$, proper catalyst selection, and a good reactor design operating under optimum reaction conditions [20].

\section{Effect of zeolite acidity}

Considering the hydrocarbon pool mechanism, the acidity of the catalyst greatly influences the productivity of the MTP reaction. H-ZSM- 5 contains both Lewis and Brønsted acid sites, and 
to evaluate accurately the catalyst activity and the product selectivity pattern, it is essential to estimate the total acidity and the quantitative number and strengths of Brønsted and Lewis sites. The strong Brønsted acidity of the catalyst initiates the reaction and contributes to the conversion of methanol, but it also accelerates coke formation. Therefore, the acidity must be adjusted $[9,10]$. Experimental results have demonstrated that the reduction of the surface acidity of H-ZSM-5 zeolite improves the catalytic stability and the selectivity of the light olefins. Decreasing the number of Brønsted acid sites of H-ZSM-5 zeolite formed by bridging $\mathrm{OH}$ groups can improve its selectivity to propylene in methanol conversion and lead to an increase in the $\mathrm{P} / \mathrm{E}$ ratio. The presence of strong acid sites results in large fractions of byproducts, especially aromatic structures, formed through hydrogen-transfer reactions and causes coke formation [10]. Several efforts have been developed to tune the acidity characteristics of ZSM-5 in the MTP reaction, such as altering the $\mathrm{Si} / \mathrm{Al}$ ratio $[30,58,59]$, hydrothermal treatment (dealumination) [60-63], and zeolite modification with the addition of promoters, including various metallic [64-75] or nonmetallic $[9,10,17,18]$ elements. These developments are discussed in the following sections.

\subsection{Effect of promoter on ZSM-5 acidity in the MTP reaction}

The inner pore system in zeolites is the catalytically active surface, and its structure depends on the composition, zeolite topology, and the nonframework cations in the interior space of channels, which may move from one site to another in the presence of adsorbed water molecules [76,77]. These cations, as mentioned before, are the compensating source of positive charge, which can be exchanged with other cations, playing a critical role in determining the catalytic nature of zeolites via interaction with Brønsted acid sites, changing the acidity of zeolites [77] and creating zeolite ion exchangers. Nonmetallic elements such as P also interact with Brønsted acid sites and alter the acidity. The type of modification procedure (e.g., incorporation, ion exchange, and impregnation) can cause different results [77-79]. Research reports have attempted to improve the selectivity of propylene and the stability of the catalyst in the MTP process with different promoters (alkali metal, alkaline earth metal, transition metal, and nonmetal), and the findings are listed in Table 1 . Both strong and weak acid sites can be regarded as the functioning sites in the MTP reaction, affecting both the selectivity to propylene and catalyst lifetime. Many researchers have suggested the conversion of some strong Brønsted acid sites of H-ZSM-5 into weak acid sites by decreasing the number of strong Brønsted acid sites with $\mathrm{P}$ attachment $[5,9,81-86]$, as shown in Scheme 7.

The proposed Model A suggests that phosphorus species in the form of elemental phosphorus at +5 oxidation state are bonded to oxygen in the zeolite framework. Thus, it is necessary to form the $\mathrm{P}-\mathrm{O}-\mathrm{Si}$ bond by dissociating the $\mathrm{Si}-\mathrm{O}-\mathrm{Al}$ bond $[87,88]$.

Determination of zeolite acidity by $\mathrm{NH}_{3}$-TPD has shown that the number of acid sites is increased significantly, whereas they are weaker compared with those in unmodified zeolite. In Model $\mathrm{B}$, the bridging $\mathrm{OH}^{-}$is replaced by $\mathrm{H}_{2} \mathrm{PO}_{4}^{-}$, and because of the electronegativity difference between the two groups $\mathrm{COH}^{-}$ and $\mathrm{H}_{2} \mathrm{PO}_{4}{ }^{-}$are 4.3 and 4.38, respectively), $\mathrm{POH}$ groups exhibit a lower acid strength than $\mathrm{Si}-\mathrm{OH}-\mathrm{Al}$ groups, and weak Brønsted acid groups are generated by $\mathrm{H}_{3} \mathrm{PO}_{4}$ [89]. A direct bond is formed between a $\mathrm{P}$ atom and the oxygen of bridging hydroxyl groups by breaking the $\mathrm{Al}-\mathrm{O}$ bond and opening the zeolite framework.

In Model C, the incorporated phosphorus species in ZSM-5 are in the form of tetrahydroxyphosphonium cations $\mathrm{P}(\mathrm{OH}) 4^{+}$ via the protonation of the orthophosphoric acid by the zeolite Brønsted sites [90]. $\mathrm{P}(\mathrm{OH}) 4^{+}$can lose a molecule of water, forming a dihydroxyoxophosphonium cation $\mathrm{PO}(\mathrm{OH})_{2}{ }^{+}$, which provides $\mathrm{H}_{5} \mathrm{P}_{2} \mathrm{O}_{7}$ with a molecule of orthophosphoric acid, as shown in Model D [90].

In Model E, two zeolite hydroxyls react with one phosphate molecule, which leads to a decrease in the number of $\mathrm{OH}$ groups that $\mathrm{P}$ can modify as shown below [91].

In all of these models, an increase in the number of acid sites is observed, together with a decrement within the structure. Phosphoric-acid-modified H-ZSM-5 (P-HZSM-5) has been employed as a catalyst [9], demonstrating a high propylene selectivity (up to $57 \%$ ) with a methanol conversion of $100 \%$ and a considerably improved catalyst stability.

Liu et al. [9] reported Si/Al = 220 for H-ZSM-5 after modification with a large variety of promoter elements such as $\mathrm{P}, \mathrm{Ce}$, W, Fe, Mn, Gr, Mo, Ga, V, and Ni. They state that propylene selectivity can be improved by $\mathrm{P}$ modification in the MTP reaction, enhancing propylene selectivity up to $55.6 \%$ in comparison with $46.4 \%$ in H-ZSM-5 and a propene to ethene ratio of 7 at full methanol conversion. The rank order of propylene selectivity (after $3 \mathrm{~h}$ on stream) for different promoters was $\mathrm{P}>\mathrm{Ce}>$ $\mathrm{W}>\mathrm{Mn}>\mathrm{Fe}>\mathrm{Gr}>\mathrm{Mo}>\mathrm{Ga}>\mathrm{V}>\mathrm{Ni}$.

Designed selectivity was stable for a long duration, up to about $100 \mathrm{~h}$ (remaining at $70.0 \%$ after $100 \mathrm{~h}$ on stream),

Table 1

Effect of various promoters on strength of acidity of ZSM-5.

\begin{tabular}{|c|c|c|c|c|c|c|c|c|}
\hline \multirow{2}{*}{ Modifier } & \multirow{2}{*}{$\mathrm{Si} / \mathrm{Al}$} & \multirow{2}{*}{ Modification } & \multicolumn{2}{|c|}{ Achievement } & \multicolumn{3}{|c|}{ Acidity $^{\text {a }}(\mathrm{mmol} / \mathrm{g})$} & \multirow{2}{*}{ Ref. } \\
\hline & & & Propylene (\%) & Life time & Strong & Weak & Total & \\
\hline $\mathrm{P}$ & 220 & impregnation & 55.6 & 4 times & $0.0172(0.0243)$ & - & - & [9] \\
\hline B & 200 & incorporation & 48.0 & 4 times & $0.103(0.116)$ & $0.140(0.102)$ & $0.243(0.218)$ & {$[10,80]$} \\
\hline Ir & $\sim 240$ & impregnation & enhanced (8\%) & slightly better & $0.198(0.288)$ & $0.288(0.281)$ & $0.486(0.569)$ & [71] \\
\hline \multirow[t]{2}{*}{$\mathrm{Ca}$} & 24 & impregnation & 50.1 & 10 times & 0.4493 & 0.6248 & 1.0741 & [67] \\
\hline & & & & & 0.0200 & 0.1385 & 0.1585 & [68] \\
\hline $\mathrm{Fe}$ & $\sim 120$ & impregnation & enhanced (6.3\%) & slightly better & $0.206(0.288)$ & $0.274(0.281)$ & $0.480(0.569)$ & [70] \\
\hline
\end{tabular}

a The number in parentheses is the acidity of parent HZSM-5. 

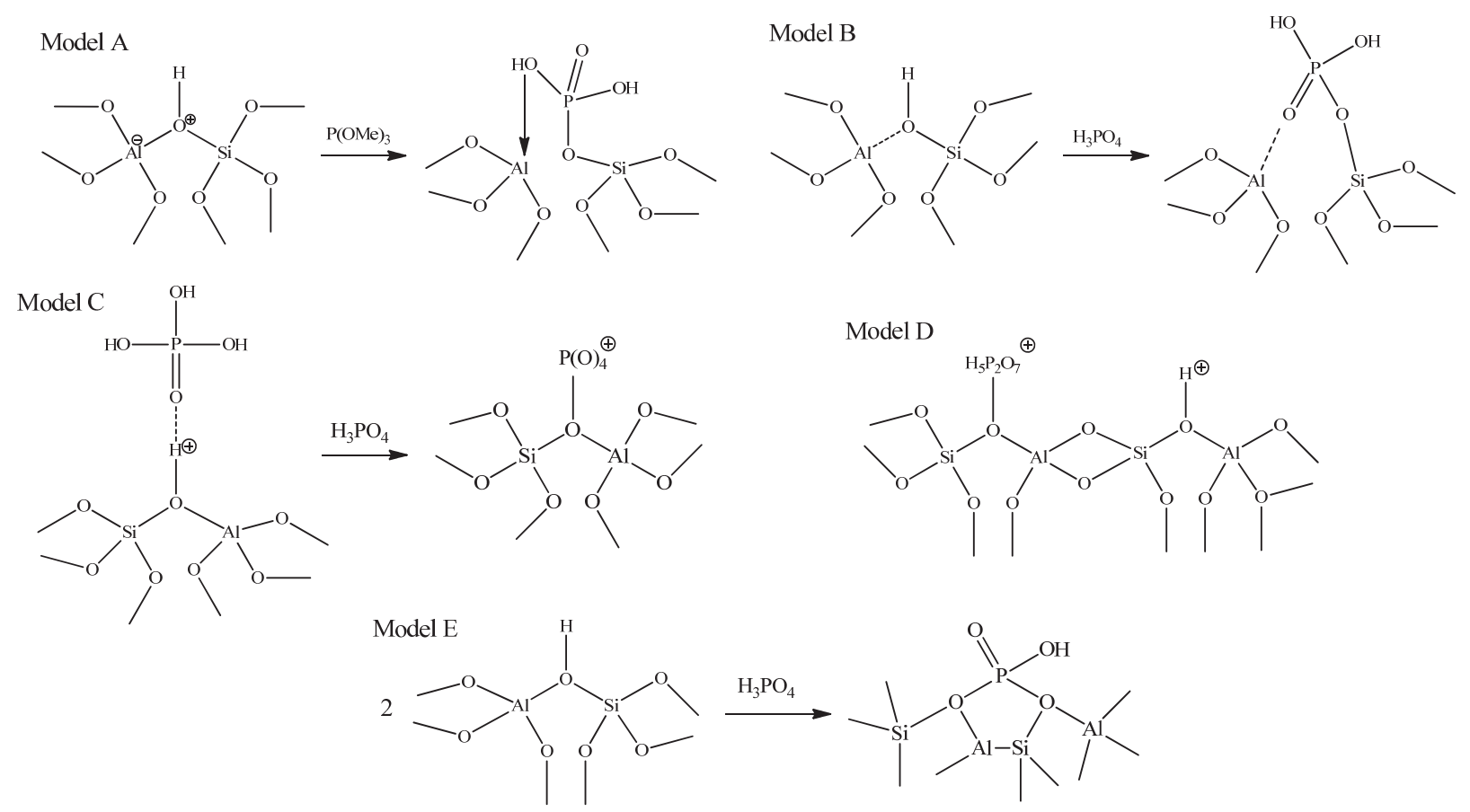

Scheme 7. Proposed models for the interaction of phosphorus species with the Brønsted acid sites of H-ZSM-5.

whereas it began to decrease at about $25 \mathrm{~h}$ for the parent ZSM-5 without P doping, decreasing to $40.5 \%$ after $85 \mathrm{~h}$ on stream under the same reaction conditions because of the full suppression of aromatics production ( $<1 \%$ selectivity) after $\mathrm{P}$ modification. The main change induced by $\mathrm{P}$ doping is partial elimination of the strong acid sites on the H-ZSM-5 catalyst by dealumination, while the pore size was maintained or slightly increased, resulting in the enhancement of shape selectivity for propylene and a remarkably prolonged catalytic lifetime [9].

Furthermore, H-ZSM-5 catalyst modification (Si/Al ratio $\approx$ 84) by $\mathrm{ZrO}_{2}$ and $\mathrm{H}_{3} \mathrm{PO}_{4}$ has been investigated as presented in Scheme 8 [5]. A P/E ratio of 10 and 45\% propene selectivity at $450{ }^{\circ} \mathrm{C}$ together with full dimethyl ether conversion were reported. After $30 \mathrm{~h}$ on stream, the P/E ratio increased up to 16 due to lower ethylene selectivity, retaining full conversion and $45 \%$ propene selectivity. After $\mathrm{ZrO}_{2}$ and $\mathrm{H}_{3} \mathrm{PO}_{4}$ modification, $\mathrm{Zr}-\mathrm{OH}$ and $\mathrm{P}-\mathrm{OH}$ acid sites are weaker than the proton acid sites of H-ZSM-5. These acid sites are intrinsically Brønsted sites, which are weaker than $\mathrm{Al}-\mathrm{OH}$ of unmodified H-ZSM-5.

$\mathrm{P}-\mathrm{O}-\mathrm{Si}$ structures (Lewis acid sites) are formed because of dehydration between $\mathrm{P}-\mathrm{OH}$ of $\mathrm{H}_{3} \mathrm{PO}_{4}$ and the hydroxyl groups that are unoccupied by the zirconium hydroxide modification, as mentioned in the modification with pure $\mathrm{H}_{3} \mathrm{PO}_{4}$ [81]. The propylene yield increments have been attributed to the ad- justment of acidity. In the other words, the number of acid sites was increased, but partly weaker in comparison with those of H-ZSM-5. These studies disclose that reducing the strong Brønsted acid sites enhances both catalytic stability and propylene selectivity. P-ZSM-5 doped with rare earth element La (P-La-ZSM-5) has been employed in MTO conversion. Catalysts contained $1.43 \% \mathrm{P}$ and $2.87 \%$ La by weight were evaluated for reaction times on stream, indicating a lifetime increase from 126 to $188 \mathrm{~h}$ and a similar overall selectivity for olefins [92].

Yang et al. [10] prepared B-Al-ZSM-5 catalysts with a controllable acidity to enable the adjustment of weak acids, while strong acids remain unchanged. The catalytic stability was significantly influenced by B incorporation, and the B-Al-ZSM-5 catalyst achieved a catalytic duration seven times that of the conventional ZSM-5 (700 and $100 \mathrm{~h}$ for B1-Al-ZSM-5 and parent ZSM-5, respectively). The improvement of catalytic stability may be attributed to the increase of weak acid sites on the ZSM-5 catalysts. A similar study has shown that the modification of nano ZSM-5 with 1 mol\% B enhanced both the catalytic stability, by retarding of coke formation, and the selectivity to propylene, because of the increase of Lewis acid sites and reduction of the Brønsted acidity [80]. Ca-modified ZSM-5 has been employed for methanol conversion, and an improvement has been observed in the catalyst performance. This effect is

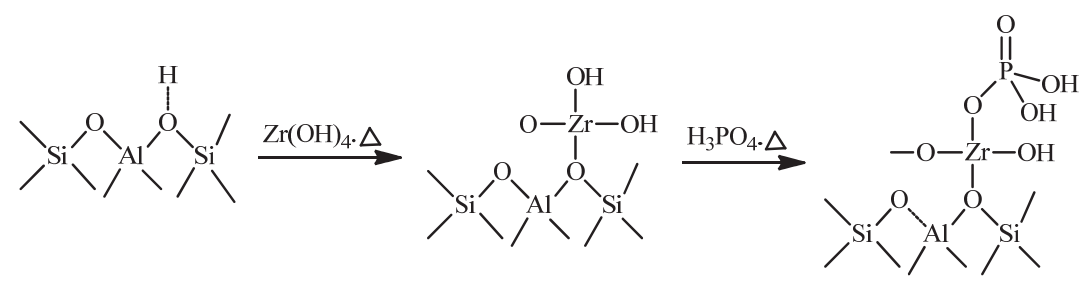

Scheme 8. Interaction of $\mathrm{ZrO}_{2}$ and $\mathrm{H}_{3} \mathrm{PO}_{4}$ by ZSM-5. 
related to the formation of active sites on the modified H-ZSM-5 zeolite by reducing strong Brønsted acid sites because of the interaction with $\mathrm{Ca}$ and the formation of $\mathrm{ZO}-\mathrm{Ca}-\mathrm{OH}$ (where $\mathrm{ZO}$ is ZSM-5). The following chemical mechanism has been suggested from the results of Py-FTIR $[67,68]$ :

$$
\begin{aligned}
\mathrm{CaO}+\mathrm{ZOH} & \rightarrow \mathrm{ZO}-\mathrm{Ca}-\mathrm{OH} \\
\mathrm{ZO}-\mathrm{Ca}-\mathrm{OH}+\mathrm{ZOH} & \rightarrow \mathrm{ZO}-\mathrm{Ca}-\mathrm{OZ}+\mathrm{H}_{2} \mathrm{O} \\
2 \mathrm{ZO}-\mathrm{Ca}-\mathrm{OH} & \rightarrow \mathrm{ZO}-\mathrm{Ca}-\mathrm{O}-\mathrm{Ca}-\mathrm{OZ}+\mathrm{H}_{2} \mathrm{O}
\end{aligned}
$$

Ca species interacting with Brønsted acid sites may hydrolyze to free Brønsted acid sites in the presence of water, and subsequently the freed Brønsted acid sites and Ca in close vicinity constituted the acid-base centers needed for the catalytic MTO transformation [67-69]. Increasing Ca loading over the H-ZSM-5 catalyst to $6 \mathrm{wt} \%$ reduced the total acid sites from 1.0741 to $0.1585 \mathrm{mmol} / \mathrm{g}$ and the amount of strong acid sites from 0.4493 to $0.020 \mathrm{mmol} / \mathrm{g}$. Ca-modified ZSM-5 has shown $50.1 \%$ selectivity to propylene in the MTP reaction, and the enhancement of the catalytic stability depends on the Ca loading [67]. Other analogs were investigated, including alkaline-metal-containing MFI zeolite crystals with a $\mathrm{Ca} / \mathrm{Al}$ atomic ratio ranging from 0.75 to 15 , for methanol conversion. The results show that in the case of $\mathrm{Ca} / \mathrm{Al}$ ratios less than 0.75 , catalyst lifetime and yield of $\mathrm{C} 2-\mathrm{C} 4$ unsaturated hydrocarbons decrease, whereas in case of ratios more than 15 , catalyst preparation is difficult [93].

$\left(\mathrm{NH}_{4}\right)_{2} \mathrm{SiF}_{6}$ solution has been used on the nanosized ZSM-5 zeolite in a reaction known as the metathesis reaction for selectively removing surface aluminum and decreasing the number of acidic sites on the H-ZSM-5 zeolite [94,95]. Dealumination by post synthetic treatment with $\left(\mathrm{NH}_{4}\right)_{2} \mathrm{SiF}_{6}$ is an effective industrial approach, which increases the framework Si/Al ratio and creates mesoporosity [96,97]. The proposed mechanism for this reaction by Min and coworkers [98] is shown in Scheme 9. In the reaction process of dealumination and silicon addition for zeolites with ammonium hexafluorosilicate solution, the ammonium hexafluorosilicate is first hydrolyzed to form $\mathrm{Si}(\mathrm{OH})_{4}$. The released $\mathrm{F}^{-}$interacts with the framework $\mathrm{Al}$ atoms

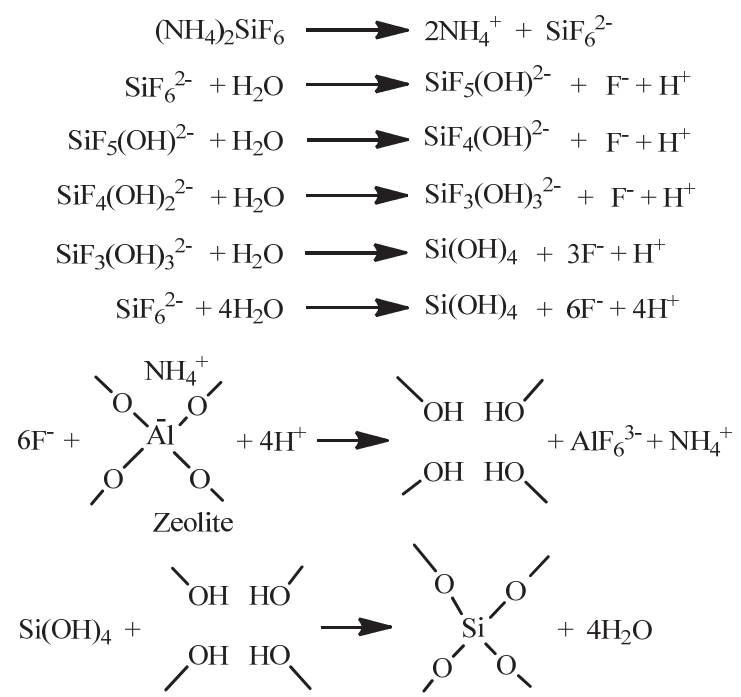

Scheme 9. Proposed mechanism for dealumination of zeolites with $\left(\mathrm{NH}_{4}\right)_{2} \mathrm{SiF}_{6}$. and is removed as $\mathrm{AlF}_{6}{ }^{3-}$. The $\mathrm{Si}(\mathrm{OH})_{4}$ molecule is inserted into the vacancy, resulting in a silicon-rich zeolite, and the isomorphous substitution reaction of framework $\mathrm{Al}$ by an extra framework $\mathrm{Si}$ is accomplished [98].

By applying the $\left(\mathrm{NH}_{4}\right)_{2} \mathrm{SiF}_{6}$ solution for dealumination of ZSM-5, the surface Si/Al ratio is increased from 26.5 to 74.6 in the optimum state. By utilizing the modified catalyst in the MTP reaction, propylene selectivity is increased from 28.8\% (in parent $\mathrm{H}-\mathrm{ZSM}-5$ zeolite) to $45.1 \%$, and the $\mathrm{P} / \mathrm{E}$ mass ratio is increased significantly from 2.6 to 8.0. In addition, the catalytic lifetime of the modified zeolite is double that of the original [91]. The acidity of zeolites is also controlled by manipulating the $\mathrm{Si} / \mathrm{Al}$ ratio $[30,58,59]$, and this ratio is an important factor in the MTO and MTP processes. A high Si/Al ratio of ZSM-5 zeolites decreases both the number of weak and strong acid sites. It cannot severely influence the product distribution determining the maximal olefin selectivity under optimized reaction conditions [2]. ZSM-5 samples with $\mathrm{Si} / \mathrm{Al}$ ratios ranging from 12 to 360 have been evaluated at $460{ }^{\circ} \mathrm{C}$, and a high Si/Al ratio of ZSM-5 zeolites has suppressed aromatization, increasing propene selectivity from $16 \%$ to $51.5 \%$. Consequently, propylene becomes the dominant product as the $\mathrm{P} / \mathrm{E}$ ratio is improved from 2.0 to 6.5 . These results show that the conversion of methanol is more stable using a catalyst with a higher $\mathrm{Si} / \mathrm{Al}$ ratio. As mentioned previously, catalyst deactivation in the MTP reaction is related to the coke formation on the catalyst surface, created by the side reactions occurring on acidic sites. These active sites are decreased as the Si/Al ratio increases, suppressing the side reactions and resulting in an improved stability. However, in the catalysts with $\mathrm{Si} / \mathrm{Al}$ ratio more than 220, the total amount of acid sites on the catalyst surface is low, and when they are covered by coke, the activity is reduced [9].

\subsection{Effect of hydrothermal treatment on ZSM-5 acidity in the MTP reaction}

The term dealumination refers to the removal of aluminum from zeolite frameworks and is one of the feasible methods for tuning the acidity of zeolites and enhancing the catalytic activity for methanol conversions, especially the MTP reaction [99-104]. Removal of aluminum from a zeolite framework was first reported in 1964 by Barrer et al. [105] when they extracted aluminum from clinoptilolite by refluxing with hydrochloric acid. Dealumination techniques are classified into two categories, extraction of framework aluminum by chemical agents, such as acids, and hydrothermal dealumination of the zeolite framework [97,106-112]. In 1986, Lago et al. [113] reported on the progressive dealumination of the framework of H-ZSM-5 using hydrothermal treatment at $540{ }^{\circ} \mathrm{C}$ in a gas stream with increasing partial pressures of water vapor up to $90 \mathrm{kPa}$. Hydrothermal treatment, mainly steaming, is widely employed to fabricate industrial ZSM-5 catalysts. Steaming at high temperatures causes dealumination of zeolite with the formation of expelled aluminum, which remains in the zeolite channel. Reducing crystallinity, surface area, and the number of Brønsted acid sites and forming Lewis acid sites after dealumination of 


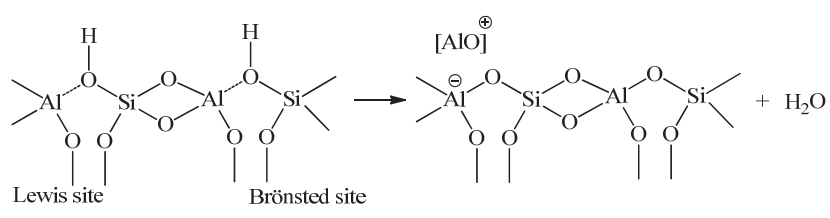

Scheme 10. Formation of Lewis acid site after dealumination of zeolite.

zeolite frameworks has been reported [99,100,114,115]. During the steaming process, fresh catalyst is calcined in a saturated atmosphere of $100 \%$ steam (in steam treatment) or in combination with $\mathrm{HCl}$ or other acids for a period of time $(10 \mathrm{~h}$ or higher) at a high temperature (400-800 ${ }^{\circ} \mathrm{C}$ ) [108-110]. ${ }^{27} \mathrm{Al}$ MAS NMR spectra results after steam treatment show that the amount of tetrahedral coordinated framework $\mathrm{Al}$ is reduced. The octahedral species increases because of the migration of $\mathrm{Al}$ species from the framework tetrahedral positions and the non-structural Al species in ZSM-5 [61]. Hydrothermal treatment provides Brønsted sites, and a framework oxygen atom is separated as water, creating a Lewis site and enlarging the volumes and diameters of the pores. The mechanism for the origin of the Lewis acid sites has been introduced by Jacobs et al. [116]. As shown in Scheme 10, the Lewis acid site is associated with the nonframework $\mathrm{Al}$ as $[\mathrm{Al}-\mathrm{O}]^{+}$.

The effect of steaming at different temperatures $(400,500$, and $700{ }^{\circ} \mathrm{C}$ ) on both microsized and nanosized H-ZSM-5 has been studied, demonstrating that under the same steaming conditions, the amount of Lewis acid sites in dealuminated nanosized H-ZSM-5 increases and easier to form compared with those in its microsized counterpart after hydrothermal treatment. A high steaming temperature reduces the intensity of Brønsted acid sites in microsized and nanosized H-ZSM-5. The catalytic activities of nano and micro H-ZSM-5 zeolites after hydrothermal treatment at different temperatures have been examined in the MTP process, obtaining improved propylene selectivity and lifetimes. Results of the catalytic performance of micro and nano H-ZSM-5 catalysts before and after hydrothermal treatment are shown in Table 2, indicating larger improvements for nanosized H-ZSM-5. However, the intense hydrothermal treatment considerably reduces the acidity, and the strongly acidic sites are almost destroyed, resulting in a significant reduction in the selectivity and stability of the catalyst $[117,63]$.

Characterizations and MTP evaluations of hydrothermally treated ZSM-5 powders and extrudates by varying temperatures and times have been investigated [101]. At the optimized treatment of $500{ }^{\circ} \mathrm{C}$ for $12 \mathrm{~h}$, the reduction of Brønsted acidity content of catalysts in powder or extruded H-ZSM-5 leads to

Table 2

Catalytic activity of micro and nano H-ZSM- 5 catalysts before (non-HT) and after hydrothermal treatment at $600{ }^{\circ} \mathrm{C}(\mathrm{HT}-600)$ or $500{ }^{\circ} \mathrm{C}(\mathrm{HT}$ $500)$.

\begin{tabular}{lcc}
\hline ZSM-5 & Selectivity to propene (\%) & Lifetime (h) \\
\hline Micro non-HT & 26.8 & 45 \\
Micro HT-600 & 33.5 & 90 \\
Nano non-HT & 30.1 & 75 \\
Nano HT-500 & 38.9 & 160 \\
\hline
\end{tabular}

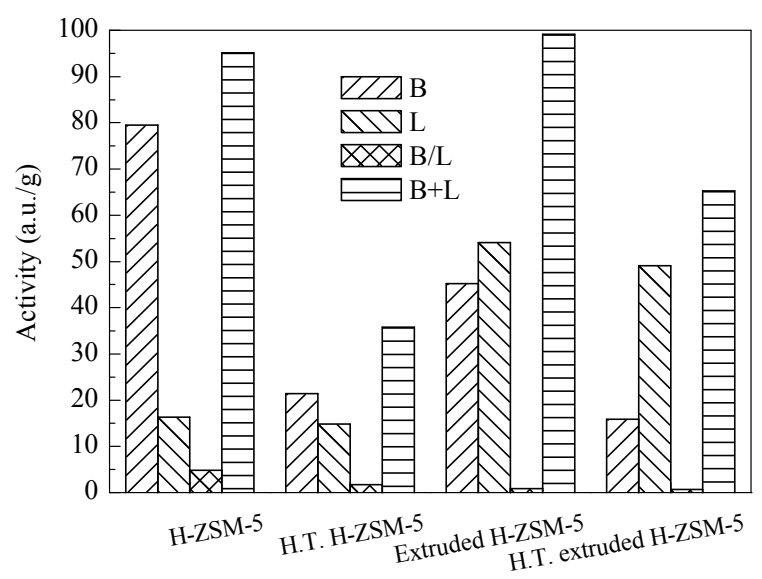

Fig. 1. Variations in acidity content of different catalysts [101].

increases in the propylene selectivity. The highest propylene selectivity (43.4\%) and longest catalytic lifetime (89 h and weight hourly space velocity of $6 \mathrm{~h}^{-1}$ ) compared with those of the non-treated extrudate $(45 \mathrm{~h})$ and treated zeolite powder (57 h) was achieved in extruded hydrothermally treated ZSM-5 because of the optimization of $\mathrm{B} / \mathrm{L}$ acid ratio and number of acid sites. Variations in acidity content of different catalysts are shown in Fig. 1.

\section{New structures as a solution for diffusion resistance}

The presence of micropores with aperture diameters below $1 \mathrm{~nm}$ in zeolites leads to diffusion limitations that adversely affect catalytic activity. Several strategies have been proposed to enhance the accessibility of active sites and shorten the diffusion path length in zeolite micropores, resulting in improved molecular diffusion. These methods include the use of nanocrystals [118-121,19] and composite materials [122-125,29] and the incorporation of intracrystalline mesoporosity $[2,126]$. For example, exfoliating layered (nanosheet) zeolites reduces the thickness of zeolite crystals, thus, reducing the diffusion path lengths and improving molecular diffusion [16]. In this section, the nanocrystal and nanosheet catalysts are reviewed.

\subsection{Effects of zeolites crystal size on the MTP reaction}

The crystal size of the zeolite is remarkably effective on their catalytic properties due to the significant differences in diffusion length of reactants and products, and in the number of strong acid sites on the surface of the catalyst. Long-term stability can be obtained using fine crystals, and the diffusion limitation increases with particle size growth in methanol conversion [127-129]. The conversion of methanol and dimethyl ether to olefins as well as coke formation is influenced by the crystal size. Rownaghi et al. [127] have employed ZSM-5 nanocrystals in the conversion of methanol to gasoline-range hydrocarbons, reporting that minimizing the crystal size significantly influences light olefin (ethylene and propylene) and paraffin (C1-C4) selectivity and the catalytic stability compared with those of conventional ZSM-5. Small-size H-ZSM-5 crystals improve the selectivity for the formation of ethylene and pro- 
pylene as well as the $\mathrm{P} / \mathrm{E}$ ratio in the catalytic conversion of methanol to hydrocarbons because of the reduction in the diffusion path in the catalysts [128]. The effect of particle size on the catalytic activity of H-ZSM-5 zeolite demonstrates that the nanoparticle size exhibits higher catalytic activity, stability, and selectivity to propylene than those of the microsized one because of its lower diffusion resistance, which accelerates the overall reaction rates $[1,130]$.

Selectivity to propylene is also increased with time (for 120 h from $42 \%$ to $63 \%$ ) for nano zeolite. The selectivity to C4 for the nano ZSM-5 is lower than that of the micro sample because fine crystals provide shorter channels; thus, the reactants contact fewer acidic sites. Therefore, higher quantities of light olefins are formed by small crystal catalysts. Due to a higher internal surface area in nanostructured ZSM-5, concentrations of the bridged hydroxyl groups (Brønsted acid sites) and nonacidic hydroxyl groups (silanols) on the external surface of the zeolites increase [131]. Decreasing the number of Brønsted acid sites of H-ZSM-5 zeolite improves its selectivity to light olefins compared with that of the heavy ones. During $8 \mathrm{~d}$ of reactor testing for different zeolite-based catalysts, the methanol conversion using the nano ZSM-5 has been consistently higher than that using the micro sized one [1]. A new approach to overcome the problem of diffusion path lengths and maximizing molecular diffusion in zeolites is to employ nanosheet zeolites in which the thickness of the zeolite crystal is reduced to a single unit cell dimension. Recently, ultrathin MFI zeolite with a 2-nm thickness has been synthesized [129,132]. Designed diquaternary ammonium-type surfactant has been used with a $\mathrm{C}_{22} \mathrm{H}_{45}-\mathrm{N}\left(\mathrm{CH}_{3}\right)_{2}-\mathrm{C}_{6} \mathrm{H}_{12}-\mathrm{N}\left(\mathrm{CH}_{3}\right)_{2}-\mathrm{C}_{6} \mathrm{H}_{13}$ formula including a long-chain alkyl group $\left(\mathrm{C}_{22}\right)$ and two quaternary ammonium groups spaced by a $\mathrm{C}_{6}$ alkyl linkage.

The ultrathin zeolite framework is formed at the hydrophilic part of the micelles, whereas the hydrophobic tail restricts the excessive growth of zeolites. This nanosheet MFI zeolite has been successfully examined in the MTP process, achieving a high propylene selectivity (51.0\%) and high P/E ratio (12.1), as well as long catalytic lifetime in the MTP reaction [16]. Ethene and total olefin selectivity can be monotonically increased with the effective crystallite size for different zeolite samples, irrespective of their synthesis; the main reasons are a higher concentration of MBs inside zeolite pores and the increased intracrystallite residence time of MBs. MBs inside the zeolite pore interact with several Brønsted acid sites during multiple aromatic ethylation/dealkylation reactions to produce light olefins from each catalytic cycle. Thus, the suggested reasons are related to the propagation of aromatic-based catalytic cycles, and the crystallite size enhances the selectivity toward ethene and light olefins in the MTO conversion by increasing the intracrystalline residence time of MBs [133].

\subsection{Effects of mesoporosity development in ZSM-5 in the MTP reaction}

In addition to nanocrystalline zeolites that permit more rapid mass transfer of reactant molecules within zeolite crystals, another approach is the presence of mesopores within zeolite crystals [134,135]. Compared with the dimensions of zeolite micropores $(<2 \mathrm{~nm})$, mesoporous zeolite structures (2-50 nm) improve the mass transfer, reduce coke deposition, and increase catalyst lifetime because of the larger pore volume of the system [136,137].

There are two main routes to fabricate mesoporous zeolites: post-treatment synthesis and template synthesis. In the post-treatment strategy, the metal element ( $\mathrm{Al}$ or $\mathrm{Si}$ ) in the zeolite structure can be extracted selectively through widely used treatments including steaming at relatively high temperature (500-600 ${ }^{\circ} \mathrm{C}$ ), acid leaching, and alkaline treatments, called dealumination or desilication when $\mathrm{Al}$ or $\mathrm{Si}$ is extracted, respectively $[137,138]$. The remaining space of $\mathrm{Al}$ or Si forms random voids in the mesoporous range in crystals. The alkaline treatment method removes mainly Si from the zeolite framework (desilication), whereas steaming and acid leaching lead to dealumination [106]. A schematic representation of the influence of the desilication treatment of MFI zeolites in $\mathrm{NaOH}$ solution is presented in Fig. 2.

The zeolite framework $\mathrm{Si} / \mathrm{Al}$ ratio affects the kinetics of the Si extraction mechanism of porosity development. At a higher density of the aluminum structure (low Si/Al ratio), higher temperatures are required to obtain some degree of mesoporosity. Because of the formation of negatively charged $\mathrm{AlO}_{4}{ }^{-}$ tetrahedra, hydrolysis of the $\mathrm{Si}-\mathrm{O}-\mathrm{Al}$ bond in the presence of $\mathrm{OH}^{-}$is hindered, and the dissolution of the zeolite framework begins from the crystalline site with the $\mathrm{Si}-\mathrm{O}-\mathrm{Si}$ bond in the absence of a neighboring Al tetrahedral $[140,141]$.

\subsubsection{Post-treatment synthesis}

In the post-treatment strategy, as mentioned above, the metal element ( $\mathrm{Al}$ or $\mathrm{Si}$ ) in zeolite structure can be selectively extracted by processes called dealumination or desilication when $\mathrm{Al}$ or Si extracted, respectively. Acid treatment is a widely used method to change the $\mathrm{SiO}_{2} / \mathrm{Al}_{2} \mathrm{O}_{3}$ ratio or the dealumination process. Most zeolites can be dealuminated by acid treatment without affecting the crystal structure of the materials. The other most commonly used dealumination methods are steaming treatment at high temperature and treatment with gaseous $\mathrm{SiCl}_{4}$ at elevated temperatures [142]. Dealumination by steaming will produce many extra framework $\mathrm{Al}$ species, which may cause detrimental effects on the catalytic and transport properties of zeolites. Therefore, subsequent acid leaching is usually applied [108]. Zeolites may undergo significant dealumination after such additional acid treatment. Dealumination is unfeasible if the aluminum concentration in ZSM-5 zeolite is low. If too many tetrahedral $\mathrm{Al}_{3}$ - ions are eliminated, many of the acid sites are lost, preventing the desirable increase of acid

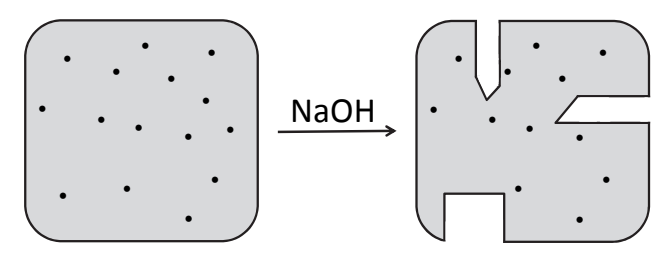

Fig. 2. Effect of the desilication treatment of MFI zeolites in $\mathrm{NaOH}$ solution [139]. 
site density. Hydrochloric acid is commonly used in acid treatment. However, long treatments can cause an undesirable effect (e.g., high dealumination and loss of structure). To prevent these effects, zeolites are realuminated by treatments with alkali solutions before acid treatment. As the framework aluminum is selectively removed, the treatment directly affects the $\mathrm{Si} / \mathrm{Al}$ ratio and Brønsted acidity. Moreover, introducing mesoporosity by dealumination is primarily effective for zeolites with a relatively high concentration of framework $\mathrm{Al}$ (low Si/Al ratios) [141], such as zeolite Y [143] and mordenite [144]. The extraction of the framework silicon, referred to as desilication, has been investigated for controlled mesopore formation in most of the zeolite frameworks containing more silicon than aluminum, particularly structures such as MFI-type zeolites. As previously mentioned, the role of aluminum on the desilication process in the MFI framework has indicated the extraction of $\mathrm{Si}$ in zeolites with a relatively high density of framework Al sites ( $\mathrm{Si} / \mathrm{Al}<20$ ), limiting pore formation and requiring the use of a higher temperature to obtain some degree of mesopore formation, whereas a relatively low $\mathrm{Al}$ content (high $\mathrm{Si} / \mathrm{Al}$ ratio) causes the opposite effect $[139,145]$. Post-treatment is a simple and economical approach in mesoporous zeolite synthesis because it can be applied to synthesized commercial zeolites and does not require any major variation in the synthesis procedure $[146,147]$. Although the mesopores obtained by this method are beneficial and improve the porosity and surface area, there are some drawbacks as follows: (1) process occurs randomly with the partial amorphization of the zeolite framework and a significant reduction of zeolite crystallinity; (2) acidic properties of modified zeolites in an uncontrolled path are changed during dealumination or desilication; (3) in demetallation processes, the aluminum content is important and only a few zeolites are suitable $[136,138,141]$.

\subsubsection{Template synthesis}

In addition to the post-treatment route, mesoporous zeolites with good crystallinity have been prepared through template synthesis. This approach is classified into hard or soft templating strategies, depending on the template source [141]. A hard template synthesis involves the use of nanostructured carbon templating, cationic polymer templating, organosilane templating or inorganic material templating [148]. The representative hard templates are carbon-based nanotemplates, including carbon nanoparticles [149,150], carbon nanotubes [151,152], carbon nanofibers [153], carbon aerogels [154], and mesoporous carbon [155].

The advantage of using nanosized carbon particles as the hard template is easy removal by calcination, but because of its hydrophobicity, it is difficult to disperse homogeneously into gels during the synthesis of zeolites. Therefore, pretreating the carbon particles in acidic or alkaline media is required, allowing formation of surface oxygen species with hydrophilic features. The compatibility of the carbon template in the synthesis solution should also be considered $[148,156]$. In addition, these hard template materials have some important limitations concerning control of the crystal size and morphology with intracrystal mesopores, and designing the degree of mesoporosi- ty. Advanced catalysts have been prepared using new templates, both soft and hard [157-161]. Recently, a novel route has been proposed for the preparation of mesopore-containing zeolite ZSM-5 via in situ hydrothermal treatment of a solution containing alkali-dissolved SBA-15 containing carbonized surfactant P123 in the mesopores, exhibiting a prominent stability enhancement for the MTP process [3]. Two other mesopore-modified high silica H-ZSM-5 zeolites have been prepared by alkaline treatment and the soft template method. A high propylene selectivity (42.2\%) and P/E ratio (10.1) in the MTP process were achieved by alkaline treatment. Another outcome was to minimize the diffusion restraints by introducing mesoporosity, which plays an important role regarding the propylene selectivity and $\mathrm{P} / \mathrm{E}$ ratio of the $\mathrm{H}-\mathrm{ZSM}-5$ catalyst and inhibits undesirable secondary reactions. The provision of open mesopore cavities or channels in H-ZSM-5 zeolite and the adjustment of its Brønsted acidity are important factors in the design of an appropriate $\mathrm{H}-\mathrm{ZSM}-5$ catalyst for the MTP reaction [2]. The influence of mesopore modification on the product selectivity of the catalyst exceeded that of the acidity [162].

\section{Effects of composite materials on catalyzing the MTP reaction}

In most industrial zeolites, to achieve the required mechanical strength and attrition resistance for large scale and form shapes as extruded pellets, a binder material is added to the zeolite. The powder form of the zeolite needs to be shaped by extrusion [163]. Synthetic materials, such as silica, alumina, and aluminum phosphate [164] or natural clays, such as kaolin and bentonite are widely employed for these purposes [165-171]. Although the binder is assumed to be inert, it may contribute to the acidity and porosity of zeolites, causing some changes in these characteristics $[165,171]$. The effects of binder materials on the catalyst characteristics can be divided into six categories [163]: (1) coking; (2) trapping of poisons; (3) transfer of chemical species to/from the active phase; (4) heat transfer; (5) porosity; (6) physical durability.

The acidities of BEA and ZSM-5 zeolites bound with bentonite have been studied, observing higher weak acidity and a lower strong acidity than binder-free zeolite. The decrease in strong acidity is related to the ion exchange of $\mathrm{Na}^{+}$in bentonite with the proton during the calcination process [172,173]. Alumina- or silica-bound ZSM-5 and Y zeolites with different Si/Al molar ratios have been investigated. The strong Lewis acidity of the catalyst with alumina binder increased because $\mathrm{Al}$ from alumina-based binders can be incorporated into the zeolite framework to form additional acid sites, whereas with the silica binder, the total acidity, strong acidity, and strength of strong acid sites were all reduced [167-170]. Researchers have succeeded in introducing a new binder that improves catalytic properties of ZSM-5 for the MTP reaction. Aluminophosphate (AlPO) binders have been prepared with amorphous phases by the addition of $\mathrm{P}$ to the pseudoboehmite, $\mathrm{AlO}(\mathrm{OH})$, for the extrusion of the ZSM-5 catalyst. The effect of binder composition on mechanical strength, acidity, and porosity of the catalyst has been studied. This novel binder did not exhibit catalytic 
self-activity, and the possible interaction of aluminum in the binder with zeolite to form additional acid sites was because of the presence of phosphorus. Unlike conventional pseudoboehmite, the AlPO binder does not release the aluminum incorporated in the zeolite lattice and exhibits no acidity increment to the zeolite. The strong acidity is reduced in this catalyst because of the interaction of $\mathrm{P}$ with the zeolite. This modification in the presence of low levels of aluminum phosphate binder (10 wt\%) led to improve the yield of propylene $(50 \%)$ at near $100 \%$ methanol conversion in the MTP reaction. The acidity can be tailored through the optimization of the $\mathrm{P}$ loading in the binder to minimize side reactions of olefins and improve the propylene yield. At the optimized P amount and reaction conditions, the catalyst exhibits a $50 \%$ yield to propylene at a near $100 \%$ conversion of methanol. Apart from the product yield, the presence of $\mathrm{P}$ in the binder also causes improved hydrothermal stability of the ZSM-5 catalyst and improved coke resistance with time-on-stream. The catalyst exhibits improved stability in methanol conversion as well as light olefin yield in the studied period of $150 \mathrm{~h}$ [7]. Similar work has been performed by Freiding et al. [174] on the MTO reaction, and $\mathrm{AlPO}_{4} / \mathrm{ZSM}-5$ has been extruded with mechanical stability.

$\mathrm{AlPO}_{4} / \mathrm{ZSM}-5$ in comparison with conventional alumina-bound samples, in which the strong acidity of the catalyst is increased because of the acidic nature of alumina, has not shown any significant increase. At temperatures above $400{ }^{\circ} \mathrm{C}$, these extrudates show superior activity, propylene selectivity, and stability [174].

The effects of single and hybrid binder systems on the acidity, mechanical strength, and catalytic performance of H-ZSM-5 zeolite $(\mathrm{Si} / \mathrm{Al}=80)$ in the MTP reaction have been investigated, evaluating different binders such as silica, alumina, and aluminum phosphate solution (APS). Similar to previous reports, the strong acidity of the catalyst is increased slightly with alumina binder, but decreased with silica and APS binders (10 wt\%), whereas zeolite with the APS binder shows the highest mechanical stability and bulk crush strength. The catalysts with hybrid binders, APS and alumina or APS and silica, present a comparable propylene selectivity to that of H-ZSM-5 with 10 $w t \%$ of APS binder, and higher mechanical stabilities [166]. The application of a catalyst comprising a physical mixture of ZSM-5 with a basic oxide of rare earth element, yttrium oxide $\left(\mathrm{Y}_{2} \mathrm{O}_{3}\right)$, has been utilized in methanol conversion to provide extended catalyst lifetime on cycle (single pass) by reducing coke formation. The cumulative methanol converted per gram of catalyst values, which is a measure of catalyst lifetime in a single cycle, in parent and modified catalysts with percentage composition 80:20 (H-ZSM-5: $\mathrm{Y}_{2} \mathrm{O}_{3}$ ) by weight, have reported 312 and $462.3 \mathrm{~g}$ methanol/ g catalyst, respectively. This improvement is a result of the binder effect of $\mathrm{Y}_{2} \mathrm{O}_{3}$ in this composite [175].

\section{Effects of zeolite topology in the MTP reaction}

The MTP process utilizes medium-pore zeolites because these structures maintain better selectivity than that of large-pore zeolites and have a longer catalyst lifetime than that of small-pore zeolites. An example of a medium-pore zeolite is H-ZSM-5 [71]. In recent years, zeolite catalysts have been studied in the methanol conversion reaction, realizing that the product selectivity and deactivation behavior of the zeolites significantly depend on their topology and pore structure [15,32,162,176-179]. These studies have shown that the catalytic mechanism shows important differences from one topology to another [34]. Therefore, the pore structure of the zeolites is important to determine their catalytic performance because the formation of active intermediates and their reaction with methanol converts them to alkenes or condensates them to polycyclic aromatic hydrocarbons, strongly depending on the pore structure [41]. The MTO reactions over various zeolites with different pore structures such as CHA, LTA, MFI, BEA, MOR, and FAU zeolites have shown that the product composition and deactivation rate on the zeolites are strongly dependent on their topology because it determines the pore entrances and cage sizes. The product selectivity divides zeolites into small-pore zeolites, such as CHA, LTA, and MOR, which show high selectivity for the lower olefins, and large-pore zeolites, such as MFI, BEA, and FAU, which are selective for aromatic structures. Moreover, the large cages of LTA and FAU zeolites allow methylbenzenes to continue condensing to polycyclic aromatic hydrocarbons, resulting in rapid deactivation through the loss of active intermediates and pore blockage. The small cages of CHA zeolite and the sinusoidal pores of MFI and BEA zeolites prevent the diffusion of the active intermediates from its cages and suppress the formation of large polycyclic aromatic hydrocarbons in their pores, which are the precursors of carbon deposits, resulting in deactivation. The deactivation rate of the zeolites in the MTO reaction is increased in the order $\mathrm{CHA} \leq \mathrm{MFI} \leq \mathrm{BEA}<\mathrm{FAU}<\mathrm{LTA}<\mathrm{MOR}$. To date, among several different acidic catalysts, mostly zeolites, high-silica ZSM-5 zeolites are the appropriate catalyst for MTP reaction [1-3,7-9]. High-silica EU-1 zeolite with $\mathrm{SiO}_{2} / \mathrm{Al}_{2} \mathrm{O}_{3}$ ratio of approximately 400 possesses a one-dimensional channel system with 10-MR and 12-MR openings with side pockets has been used in the MTP reaction. For EU-1, the propylene selectivity and $\mathrm{P} / \mathrm{E}$ ratio were $52 \%$ and 15 , and the catalytic mechanism was mainly governed by narrow 10 -MR channels. However, the order of catalytic stability for the zeolite catalysts during the MTP reaction was ZSM-5 > BEA > EU-1 > ZSM-48. EU-1 requires appropriate technology due to its low lifetime in comparison with ZSM-5 and BEA. The channels of H-ZSM-48 are easily blocked by coke species, and this may be responsible for its rapid deactivation in the MTP conversion [15].

Four zeolites with different topologies, SAPO-34, ZSM-48, ZSM-5, and BEA, showed that the small-pore CHA (SAPO-34) zeolites have the highest selectivity to the lower olefins, whereas the large-pore BEA zeolites showed a low propylene selectivity because of the product distribution to heavier hydrocarbons [180]. The catalytic behavior of H-ZSM-5 and HMOR zeolites were tested in the MTP reaction. The propylene selectivity of the HMOR catalyst was double that of H-ZSM-5, whereas the C1-C4 hydrocarbon and ethylene selectivity were decreased. Variations in product distribution can be related to the reduction in strong acidity as well as the attenuation of 
strong acid strength in HMOR. Furthermore, HMOR has a much higher mesopore volume compared with that of H-ZSM-5, and the catalytic stability of HMOR is higher than that of H-ZSM-5 because of the influence of mesoporosity and the improvement of the diffusion of the gas molecules. The low propylene production and low stability of H-ZSM-5 zeolite is related to the low Si/Al molar ratio $(<100)$ [162].

\section{Outlook}

ZSM-5-based catalysts remain the most promising industrial catalysts for the MTP reaction due to their long lifetimes and high selectivity to propylene. By discussing the outcome of research efforts, this contribution demonstrates that ZSM-5 zeolite with some amendments is able to provide acceptable results for the MTP process. Over the coming years, our knowledge about zeolites and heterogeneous catalysis may advance to include new generations of modified catalysts and the systematic application of efficient techniques for understanding the mechanisms required for further catalyst development. Further improvements of current catalysts can be expected by enhancing the acidity, mesoporosity, crystal size, and morphology. These factors as well as the tuning of operating reactor conditions such as temperature, pressure, weight hourly space velocity, and co-feeding are key process parameters to optimize the product selectivity towards propylene. Taking into account the tremendously fast growing application of nanotechnology, cost effective nanocatalysts are the next generation of promoters and will soon be commercially available. Environmentally friendly catalysts, which can be reproduced easily, will also prove important in the future.

\section{References}

[1] M. Firoozi, M. Baghalha, M. Asadi, Catal. Commun., 2009, 10, 1582-1585.

[2] C. S. Mei, P. Y. Wen, Z. C. Liu, H. X. Liu, Y. D. Wang, W. M. Yang, Z. K. Xie, W. M. Hua, Z. Gao, J. Catal., 2008, 258, 243-249.

[3] C. Sun, J. M. Du, J. Liu, Y. S. Yang, N. Ren, W. Shen, H. L. Xu, Y. Tang, Chem. Commun., 2010, 46, 2671-2673.

[4] G. L. Zhao, J. W. Teng, Z. K. Xie, W. Q. Jin, W. M. Yang, Q. L. Chen, Y. Tang, J. Catal., 2007, 248, 29-37.

[5] T. S. Zhao, T. Takemoto, N. Tsubaki, Catal. Commun., 2006, 7, 647-650.

[6] H. Koempel, W. Liebner, Stud. Surf. Sci. Catal., 2007, 167, 261-267.

[7] Y. J. Lee, Y. W. Kim, N. Viswanadham, K. W. Jun, J. W. Bae, Appl. Catal. A, 2010, 374, 18-25.

[8] W. Z. Wu, W. Y. Guo, W. D. Xiao, M. Luo, Chem. Eng. Sci., 2011, 66, $4722-4732$.

[9] J. Liu, C. X. Zhang, Z. H. Shen, W. M. Hua, Y. Tang, W. Shen, Y. H. Yue, H. L. Xu, Catal. Commun., 2009, 10, 1506-1509.

[10] Y. S. Yang, C. Sun, J. M. Du, Y. H. Yue, W. M. Hua, C. L. Zhang, W. Shen, H. L. Xu, Catal. Commun., 2012, 24, 44-47.

[11] P. Tian, Y. X. Wei, M. Ye, Z. M. Liu, ACS Catal., 2015, 5, 1922-1938.

[12] S. Ritter, Chem. Eng. News, 2015, 93, 30-31.

[13] X. C. Wu, M. G. Abraha, R. G. Anthony, Appl. Catal. A, 2004, 260, 63-69.

[14] M. Stöcker, Microporous Mesoporous Mater., 1999, 29, 3-48.
[15] S. Hu, Y. J. Gong, Q. H. Xu, X. L. Liu, Q. Zhang, L. L. Zhang, T. Dou, Catal. Commun., 2012, 28, 95-99.

[16] S. Hu, J. Shan, Q. Zhang, Y. Wang, Y. S. Liu, Y. J. Gong, Z. J. Wu, T. Dou, Appl. Catal. A, 2012, 445-446, 215-220.

[17] A. N. Xu, H. F. Ma, H. T. Zhang, W. Y. Ying, D. Y. Fang, Polish J. Chem. Technol., 2013, 15, 95-101.

[18] F. Bleken, M. Bjørgen, L. Palumbo, S. Bordiga, S. Svelle, K. P. Lillerud, U. Olsbye, Top. Catal., 2009, 52, 218-228.

[19] H. G. Jang, H. K. Min, J. K. Lee, S. B. Hong, G. Seo, Appl. Catal. A, 2012, 437-438, 120-130.

[20] H. Schulz, Catal. Today, 2010, 154, 183-194.

[21] M. Hack, U. Koss, P. König, M. Rothaemel, H. D. Holtmann, WO Patent 0192190A1, 2001.

[22] M. Hack, U. Koss, P. König, M. Rothaemel, H. D. Holtmann, US Patent 7015369B2, 2006.

[23] R. Bauman, R. Fiato, US Patent 0174129A1, 2010.

[24] P. Su, US Patent 0303819A1, 2013.

[25] T. Setoyama, Y. Yoshikawa, K. Nakagawa, US Patent 0229482A1, 2006.

[26] T. N. Kalnes, D. H. Wei, B. K. Glover, US Patent 7663012B2, 2010.

[27] M. Rostamizadeha, A. Taeb, J. Ind. Eng. Chem., 2015, 27, 297-306.

[28] F. L. Bleken, S. Chavan, U. Olsbye, M. Boltz, F. Ocampo, B. Louis, Appl. Catal. A, 2012, 447-448, 178-185.

[29] S. Ivanova, C. Lebrun, E. Vanhaecke, C. Pham-Huu, B. Louis, J. Catal., 2009, 265, 1-7.

[30] R. C. Wei, C. Y. Li, C. H. Yang, H. H. Shan, J. Nat. Gas Chem., 2011, 20, 261-265.

[31] C. M. Wang, Y. D. Wang, Z. K. Xie, J. Catal., 2013, 301, 8-19.

[32] H. K. Min, M. B. Park, S. B. Hong, J. Catal,, 2010, 271, 186-194.

[33] W. G. Song, D. M. Marcus, H. Fu, J. O. Ehresmann, J. F. Haw, J. Am. Chem. Soc., 2002, 124, 3844-3845.

[34] M. Bjørgen, F. Joensen, K. P. Lillerud, U. Olsbye, S. Svelle, Catal. Today, 2009, 142, 90-97.

[35] I. M. Dahl, S. Kolboe, Catal. Lett., 1993, 20, 329-336.

[36] I. M. Dahl, S. Kolboe, J. Catal., 1994, 149, 458-464.

[37] I. M. Dahl, S. Kolboe, J. Catal., 1996, 161, 304-309.

[38] W. Wang, A. Buchholz, M. Seiler, M. Hunger, J. Am. Chem. Soc., 2003, 125, 15260-15267.

[39] M. Bjørgen, U. Olsbye, S. Kolboe, J. Catal., 2003, 215, 30-44.

[40] M. Bjørgen, U. Olsbye, D. Petersen, S. Kolboe, J. Catal., 2004, 221, $1-10$.

[41] J. W. Park, G. Seo, Appl. Catal. A, 2009, 356, 180-188.

[42] A. Sassi, M. A. Wildman, H. J. Ahn, P. Prasad, J. B. Nicholas, J. F. Haw, J. Phys. Chem. B, 2002, 106, 2294-2303.

[43] B. Arstad, S. Kolboe, J. Am. Chem. Soc., 2001, 123, 8137-8138.

[44] C. Wang, Y. Y. Chu, A. M. Zheng, J. Xu, Q. Wang, P. Gao, G. D. Qi, Y. J. Gong, F. Deng, Chem. Eur. J., 2014, 20, 12432-12443.

[45] S. Svelle, U. Olsbye, F. Joensen, M. Bjørgen, J. Phys. Chem. C, 2007, 111, 17981-17984.

[46] S. Svelle, F. Joensen, J. Nerlov, U. Olsbye, K. P. Lillerud, S. Kolboe, M. Bjørgen, J. Am. Chem. Soc., 2006, 128, 14770-14771.

[47] M. Bjørgen, S. Svelle, F. Joensen, J. Nerlov, S. Kolboe, F. Bonino, L. Palumbo, S. Bordiga, U. Olsbye, J. Catal., 2007, 249, 195-207.

[48] R. Khare, A. Bhan, J. Catal., 2015, 329, 218-228.

[49] S. Ilias, A. Bhan, J. Catal., 2014, 311, 6-16.

[50] J. C. Zhang, H. B. Zhang, X. Y. Yang, Z. Huang, W. L. Cao, J. Nat. Gas Chem., 2011, 20, 266-270.

[51] D. M. Bibby, R. F. Howe, G. D. Mclellan, Appl. Catal. A, 1992, 93, 1-34.

[52] M. Guisnet, P. Magnoux, Appl. Catal., 1989, 54, 1-27.

[53] D. Mores, E. Stavitski, M. H. F. Kox, J. Kornatowski, U. Olsbye, B. M. Weckhuysen, Chem. Eur. J., 2008, 14, 11320-11327. 
[54] J. Li, G. Xiong, Z. Feng, Z. Liu, Q. Xin, C. Li, Microporous Mesoporous Mater., 2000, 39, 275-280.

[55] S. Müller, Y. Liu, M. Vishnuvarthan, X. Y. Sun, A. C. van Veen, G. L. Haller, M. Sanchez-Sanchez, J. A. Lercher, J. Catal., 2015, 325, 48-59.

[56] N. Y. Topsøe, K. Pedersen, E. G. Derouane, J. Catal., 1981, 70, 41-52.

[57] D. Mores, J. Kornatowski, U. Olsbye, B. M. Weckhuysen, Chem. Eur. J., 2011, 17, 2874-2884.

[58] C. D. Chang, C. T. W. Chu, R. F. Socha, J. Catal., 1984, 86, 289-296.

[59] A. G. Gayubo, P. L. Benito, A. T. Aguayo, M. Olazar, J. Bilbao, J. Chem. Technol. Biotechnol., 1996, 65, 186-192.

[60] L. H. Ong, M. Dömök, R. Olindo, A. C. van Veen, J. A. Lercher, Microporous Mesoporous Mater., 2012, 164, 9-20.

[61] W. P. Zhang, X. W. Han, X. M. Liu, X. H. Bao, J. Mol. Catal. A, 2003, 194, 107-113.

[62] V. S. Nayak, V. R. Choudhary, Appl. Catal., 1984, 10, 137-145.

[63] D. S. Mao, S. Q. Guo, T. Meng, G. Z. Lu, Acta Phys. Chim. Sin., 2010, 26, 338-344.

[64] N. Hadi, A. Niaei, S. R. Nabavi, R. Alizadeh, M. N. Shirazi, B. Izadkhah, J. Taiwan Inst. Chem. Eng., 2016, http://dx.doi.org/ 10.1016/j.jtice.2015.09.017.

[65] B. Valle, A. Alonso, A. Atutxa, A. G. Gayubo, J. Bilbao, Catal. Today, 2005, 106, 118-122.

[66] C. Sun, Y. S. Yang, J. M. Du, F. Qin, Z. P. Liu, W. Shen, H. L. Xu, Y. Tang, Chem. Commun., 2012, 48, 5787-5789.

[67] S. H. Zhang, B. L. Zhang, Z. X. Gao, Y. Z. Han, React. Kinet, Mechan. Catal., 2010, 99, 447-453.

[68] S. H. Zhang, B. L. Zhang, Z. X. Gao, Y. Z. Han, Ind. Eng. Chem. Res., 2010, 49, 2103-2106.

[69] J. M. Man, Q. D. Zhang, H. J. Xie, J. X. Pan, Y. S. Tan, Y. Z. Han, J. Fuel Chem. Technol., 2011, 39, 42-46.

[70] A. Mohammadrezaei, S. Papari, M. Asadi, A. Naderifar, R. Golhosseini, Frontiers Chem. Sci. Eng., 2012, 6, 253-258.

[71] S. Papari, A. Mohammadrezaei, M. Asadi, R. Golhosseini, A. Naderifar, Catal. Commun., 2011, 16, 150-154.

[72] N. Hadi, A. Niaei, S. R. Nabavi, A. Farzi, M. Navaei, Chem. Biochem. Eng. Q., 2014, 28, 53-63.

[73] N. Hadi, A. Niaei, S. R. Nabavi, M. Navaei Shirazi, R. Alizadeh, J. Ind. Eng. Chem., 2015, 29, 52-62.

[74] P. Ciambelli, G. Bagnasco, P. Corbo, Stud. Surf. Sci. Catal., 1989, 44, 239-246.

[75] A. M. Al-Jarallah, U. A. El-Nafaty, M. M. Abdillahi, Appl. Catal. A, 1997, 154, 117-127.

[76] E. Beerdsen, D. Dubbeldam, B. Smit, T. J. H. Vlugt, S. Calero, J. Phys. Chem. B, 2003, 107, 12088-12096.

[77] G. Ciobanu, D. Ignat, G. Carja, S. Ratoi, C. Luca, Chem. Bull. "POLITEHNICA" Univ. (Timisoara), 2008, 53, 200-203.

[78] W. Q. Wu, E. Weitz, Appl. Surf. Sci., 2014, 316, 405-415.

[79] N. Kumar, L. E. Lindfors, Catal. Lett., 1996, 38, 239-244.

[80] F. Yaripour, Z. Shariatinia, S. Sahebdelfar, A. Irandoukht, Microporous Mesoporous Mater., 2015, 203, 41-53.

[81] D. V. Vu, Y. Hirota, N. Nishiyama, Y. Egashira, K. Ueyama, J. Jpn. Petrol. Inst., 2010, 53, 232-238

[82] Z. da Silva Barros, F. M. Z. Zotin, C. A. Henriques, Stud. Surf. Sci. Catal., 2007, 167, 255-260.

[83] P. Li, W. P. Zhang, X. W. Han, X. H. Bao, Catal. Lett., 2010, 134, 124-130.

[84] T. W. Beutel, S. J. Mccarthy, B. Waldrup, M. Daage, K. J. Hickey, WO Patent 059162A1, 2013.

[85] M. Kaarsholm, F. Joensen, J. Nerlov, R. Cenni, J. Chaouki, G. S. Patience, Chem. Eng. Sci., 2007, 62, 5527-5532.
[86] D. S. Mao, Q. S. Guo, G. Z. Lu, Acta Petrol. Sin. (Petrol. Processing Sect.), 2009, 25, 503-508.

[87] W. W. Kaeding, S. A. Butter, J. Catal., 1980, 61, 155-164.

[88] J. C. Vedrine, A. Auroux, P. Dejaifve, V. Ducarme, H. Hoser, S. B. Zhou, J. Catal., 1982, 73, 147-160.

[89] J. A. Lercher, G. Rumplmayr, Appl. Catal., 1986, 25, 215-222.

[90] T. Blasco, A. Corma, J. Martínez-Triguero, J. Catal., 2006, 237, 267-277.

[91] N. H. Xue, X. K. Chen, L. Nie, X. F. Guo, W. P. Ding, Y. Chen, M. Gu, Z. K. Xie, J. Catal., 2007, 248, 20-28.

[92] G. W. Wang, M. L. Ying, X. C. Wang, G. Q. Chen, US Patent 5367100A, 1994.

[93] H. Ito, K. Ooyama, S. Yamada, M. Kume, N. Chikamatsu, US Patent 0032379A1, 2007.

[94] S. Hu, Q. Zhang, Z. Xia, Y. J. Gong, J. Xu, F. Deng, T. Dou, Acta Phys. Chim. Sin., 2012, 28, 2705-2712.

[95] S. Han, D. S. Shihabi, C. D. Chang, J. Catal., 2000, 196, 375-378.

[96] F. Kollmer, H. Hausmann, W. F. Hoelderich, J. Catal., 2004, 227, 408-418.

[97] Z. X. Qin, J. P. Gilson, V. Valtchev, Curr. Opin. Chem. Eng., 2015, 8, $1-6$.

[98] Y. G. He, C. Y. Li, E. Z. Min, Stud. Surf. Sci. Catal., 1989, 49, 189-197.

[99] L. R. Aramburo, L. C. Karwacki, P. Cubillas, S. Asahina, D. A. M. de Winter, M. R. Drury, I. L. C. Buurmans, E. Stavitski, D. Mores, M. Daturi, P. Bazin, P. Dumas, F. Thibault-Starzyk, J. A. Post, M. W. Anderson, O. Terasaki, B. M. Weckhuysen, Chem. Eur. J., 2011, 17, 13773-13781.

[100] J. L. Wan, Y. X. Wei, Z. M. Liu, B. Li, Y. Qi, M. Z. Li, P. Xie, S. H. Meng, Y. L. He, F. X. Chang, Catal. Lett., 2008, 124, 150-156.

[101] S. L. Zhang, Y. J. Gong, L. L. Zhang, Y. S. Liu, T. Dou, J. Xu, F. Deng, Fuel Processing Technol., 2015, 129, 130-138.

[102] C. S. Triantafillidis, A. G. Vlessidis, L. Nalbandian, N. P. Evmiridis, Microporous Mesoporous Mater., 2001, 47, 369-388.

[103] S. M. T. Almutairi, B. Mezari, E. A. Pidko, P. C. M. M. Magusin, E. J. M. Hensen, J. Catal., 2013, 307, 194-203.

[104] H. K. Beyer, Mol. Sieves, 2002, 3, 203-255.

[105] R. M. Barrer, M. B. Makki, Can. J. Chem., 1964, 42, 1481-1487.

[106] Z. Qin, L. Lakiss, J. P. Gilson, K. Thomas, J. M. Goupil, C. Fernandez, V. Valtchev, Chem. Mater., 2013, 25, 2759-2766.

[107] Y. Oumi, S. Nemoto, S. Nawata, T. Fukushima, T. Teranishi, T. Sano, Mater. Chem. Phys., 2002, 78, 551-557.

[108] Y. Fan, X. J. Bao, X. Y. Lin, G. Shi, H. Y. Liu, J. Phys. Chem. B, 2006, $110,15411-15416$

[109] S. M. Campbell, D. M. Bibby, J. M. Coddington, R. F. Howe, J. Catal., 1996, 161, 350-358.

[110] A. de Lucas, P. Canizares, A. Durhn, A. Carrero, Appl. Catal. A, 1997, 154, 221-240.

[111] M. D. Gonzalez, Y. Cesteros, P. Salagre, Microporous Mesoporous Mater., 2011, 144, 162-170.

[112] R. R. Xu, W. Q. Pang, J. H. Yu, Q. S. Huo, J. S. Chen, Chemistry of Zeolites and Related Porous Materials: Synthesis and Structure, John Wiley \& Sons (Asia) Pte Ltd, Singapore, 2007.

[113] R. M. Lago, W. O. Haag, R. J. Mikovsky, D. H. Olson, S. D. Hellring, K. D. Schmitt, G. T. Kerr, Stud. Surf. Sci. Catal., 1986, 28, 677-684.

[114] Y. W. Zhang, Y. M. Zhou, K. Z. Yang, Y. Li, Y. Wang, Y. Xu, P. C. Wu, Microporous Mesoporous Mater., 2006, 96, 245-254.

[115] P. Praserthdam, N. Mongkolsiri, P. Kanchanawanichkun, Catal. Commun., 2002, 3, 191-197.

[116] P. A. Jacobs, H. K. Beyer, J. Phys. Chem., 1979, 83, 1174-1177.

[117] L. Y. Fang, Y. C. Cheng, Ind. Catal., 2012, 20(9), 40-46.

[118] T. Tago, T. Masuda, in: Y. Masuma ed., Nanocrystals, InTech Open 
Access Publisher, 2010, 191-206.

[119] F. Wang, Q. Zhang, S. Hu, Y. J. Gong, T. Dou, Ind. Catal., 2012, 20(7), 17-21.

[120] M. Yao, S. Hu, J. Wang, T. Dou, Y. P. Wu, Acta Phys. Chim. Sin., 2012, 28, 2122-2128.

[121] T. Armaroli, L. J. Simon, M. Digne, T. Montanari, M. Bevilacqua, V. Valtchev, J. Patarin, G. Busca, Appl. Catal. A, 2006, 306, 78-84.

[122] Y. L. Jiao, C. H. Jiang, Z. M. Yang, J. S. Zhang, Microporous Mesoporous Mater., 2012, 162, 152-158.

[123] S. Ivanova, B. Louis, B. Madani, J. P. Tessonnier, M. J. Ledoux, C. Pham-Huu, J. Phys. Chem. C, 2007, 111, 4368-4374.

[124] S. Ivanova, E. Vanhaecke, L. Dreibine, B. Louis, C. Pham, C. Pham-Huu, Appl. Catal. A, 2009, 359, 151-157.

[125] M. Wen, X. Y. Wang, L. P. Han, J. Ding, Y. Sun, Y. Liu, Y. Lu, Microporous Mesoporous Mater., 2015, 206, 8-16.

[126] K. Egeblad, C. H. Christensen, M. Kustova, C. H. Christensen, Chem. Mater., 2008, 20, 946-960.

[127] A. A. Rownaghi, F. Rezaei, J. Hedlund, Catal. Commun., 2011, 14, 37-41.

[128] D. Prinz, L. Riekert, Appl. Catal., 1988, 37, 139-154.

[129] M. Choi, K. Na, J. Kim, Y. Sakamoto, O. Terasaki, R. Ryoo, Nature, 2009, 461, 246-249.

[130] D. Chen, K. Moljord, T. Fuglerud, A. Holmen, Microporous Mesoporous Mater., 1999, 29, 191-203.

[131] W. P. Zhang, X. H. Bao, X. W. Guo, X. S. Wang, Catal. Lett., 1999, 60, 89-94.

[132] W. Park, D. Yu, K. Na, K. E. Jelfs, B. Slater, Y. Sakamoto, R. Ryoo, Chem. Mater., 2011, 23, 5131-5137.

[133] R. Khare, D. Millar, A. Bhan, J. Catal., 2015, 321, 23-31.

[134] S. van Donk, A. H. Janssen, J. H. Bitter, K. P. de Jong, Catal. Rev.-Sci. Eng., 2003, 45, 297-319.

[135] X. Y. Li, M. H. Sun, J. C. Rooke, L. H. Chen, B. L. Su, Chin. J. Catal., 2013, 34, 22-47.

[136] J. Zhu, X. J. Meng, F. S. Xiao, Frontiers Chem. Sci. Eng., 2013, 7, 233-248.

[137] Y. S. Tao, H. Kanoh, L. Abrams, K. Kaneko, Chem. Rev., 2006, 106, 896-910.

[138] K. Na, M. Choi, R. Ryoo, Microporous Mesoporous Mater., 2013, 166, 3-19.

[139] J. C. Groen, J. C. Jansen, J. A. Moulijn, J. Perez-Ramirez, J. Phys. Chem. B, 2004, 108, 13062-13065.

[140] L. L. Su, L. Liu, J. Q. Zhuang, H. X. Wang, Y. G. Li, W. J. Shen, Y. D. Xu,
Catal. Lett., 2003, 91, 155-167.

[141] Y. Wang, S. Wang, Open J. Adv. Mater. Res., 2013, 1(2), 13-23.

[142] P. J. Kooyman, P. van der Waal, H. van Bekkum, Zeolites, 1997, 18, 50-53.

[143] C. S. Triantafillidis, A. G. Vlessidis, N. P. Evmiridis, Ind. Eng. Chem. Res., 2000, 39, 307-319.

[144] N. S. Nesterenko, F. Thibault-Starzyk, V. Montouillout, V. V. Yuschenko, C. Fernandez, J. P. Gilson, F. Fajula, I. I. Ivanova, Microporous Mesoporous Mater., 2004, 71, 157-166.

[145] K. Moller, T. Bein, Chem. Soc. Rev., 2013, 42, 3689-3707.

[146] S. Lopez-Orozco, A. Inayat, A. Schwab, T. Selvam, W. Schwieger, Adv. Mater., 2011, 23, 2602-2615.

[147] A. Taguchi, F. Schüth, Microporous Mesoporous Mater., 2005, 77, $1-45$.

[148] X. J. Meng, F. Nawaz, F. S. Xiao, Nano Today, 2009, 4, 292-301.

[149] C. J. H. Jacobsen, C. Madsen, J. Houzvicka, I. Schmidt, A. Carlsson, J. Am. Chem. Soc., 2000, 122, 7116-7117.

[150] J. Kim, M. Choi, R. Ryoo, J. Catal., 2010, 269, 219-228.

[151] I. Schmidt, A. Boisen, E. Gustavsson, K. Stahl, S. Pehrson, S. Dahl, A. Carlsson, C. J. H. Jacobsen, Chem. Mater., 2001, 13, 4416-4418.

[152] A. Boisen, I. Schmidt, A. Carlsson, S. Dahl, M. Brorson, C. J. H. Jacobsen, Chem. Commun., 2003, 958-959.

[153] A. H. Janssen, I. Schmidt, C. J. H. Jacobsen, A. J. Koster, K. P. de Jong, Microporous Mesoporous Mater., 2003, 65, 59-75.

[154] Y. S. Tao, H. Kanoh, K. Kaneko, J. Am. Chem. Soc., 2003, 125, 6044-6045.

[155] Z. X. Yang, Y. D. Xia, R. Mokaya, Adv. Mater., 2004, 16, 727-732.

[156] L. F. Wang, Z. Zhang, C. Y. Yin, Z. C. Shan, F. S. Xiao, Microporous Mesoporous Mater., 2010, 131, 58-67.

[157] H. X. Tao, H. Yang, X. H. Liu, J. W. Ren, Y. Q. Wang, G. Z. Lu, Chem. Eng. J., 2013, 225, 686-694.

[158] R. W. Wang, W. T. Liu, S. Ding, Z. T. Zhang, J. X. Li, S. L. Qiu, Chem. Commun., 2010, 46, 7418-7420.

[159] J. Perez-Ramírez, S. Abello, A. Bonia, G. C. Groen, Adv. Funct. Mater., 2009, 19, 164-172.

[160] X. Li, B. S. Li, J. Q. Xu, Colloids Surf. A, 2013, 434, 287-295.

[161] J. Ahmadpour, M. Taghizadeh, J. Nat. Gas Sci. Eng., 2015, 23, 184-194.

[162] J. C. Moreno-Pirajan, V. S. Garcia-Cuello, L. Giraldo, J. Thermodyn. Catal., 2010, 1, 101-108.

[163] J. S. J. Hargreaves, A. L. Munnoch, Catal. Sci. Technol., 2013, 3, 1165-1171.

\section{Graphical Abstract}

\section{Chin. J. Catal., 2016, 37: 325-339 doi: 10.1016/S1872-2067(15)61031-2}

\section{Methanol-to-propylene process: Perspective of the most important catalysts and their behavior}

M. Khanmohammadi *, Sh. Amani, A. Bagheri Garmarudi, A. Niaei

Imam Khomeini International University, Iran; University of Tabriz, Iran

Various acidic catalysts, mostly zeolites, have been evaluated for methanol conversion to propyele. Zeolites-microporous crystalline aluminosilicates and their ZSM-5 forms are widely used in methanol-to-propylene (MTP) process because of their strong acid sites within uniform micropores as size and shape selective catalysts.

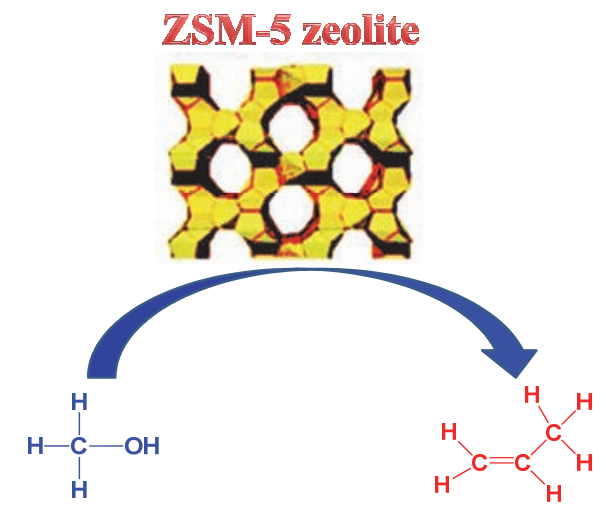


[164] G. Burgfels, K. Kochloefl, J. Ladebeck, M. Schneider, F. Schmidt, H. J. Wernicke, J. Schonlinner, US Patent 0138053A1, 2004.

[165] J. Freiding, F. C. Patcas, B. Kraushaar-Czarnetzki, Appl. Catal. A, 2007, 328, 210-218.

[166] K. Y. Lee, H. K. Lee, S. K. Ihm, Top. Catal., 2010, 53, 247-253.

[167] X. Wu, A. Alkhawaldeh, R. G. Anthony, Stud. Surf. Sci. Catal., 2000, $143,217-225$.

[168] S. D. Kim, S. C. Baek, Y. J. Lee, K. W. Jun, M. J. Kim, I. S. Yoo, Appl. Catal. A, 2006, 309, 139-143.

[169] S. Hajimirzaee, M. Ainte, B. Soltani, R. M. Behbahani, G. A. Leeke, J. Wood, Chem. Eng. Res. Des., 2015, 93, 541-553.

[170] A. K. Ghosh, C. Mihut, M. Simmons, US Patent 2014080696A1, 2014.

[171] R. V. Jasra, B. Tyagi, Y. M. Badheka, V. N. Choudary, T. S. G. Bhat, Ind. Eng. Chem. Res., 2003, 42, 3263-3272.

[172] P. Sanchez, F. Dorado, A. Funez, V. Jimenez, M. J. Ramos, J. L. Valverde, J. Mol. Catal. A, 2007, 273, 109-113.
[173] A. de Lucas, J. L. Valverde, P. Sánchez, F. Dorado, M. J. Ramos, Ind. Eng. Chem. Res, 2004, 43, 8217-8225.

[174] J. Freiding, B. Kraushaar-Czarnetzki, Appl. Catal. A, 2011, 391, 254-260.

[175] L. R. M. Martens, D. M. Marcus, T. Xu, US Patent 0099913A1, 2015.

[176] S. Teketela, U. Olsbyea, K. P. Lilleruda, P. Beatob, S. Svellea, Appl. Catal. A, 2015, 494, 68-76.

[177] L. L. Wu, V. Degirmenci, P. C. M. M. Magusin , N. J. H. G. M. Lousberg , E. J. M. Hensen, J. Catal., 2013, 298, 27-40.

[178] X. J. Meng, Q. J. Yu, Y. A. Gao, Q. Zhang, C. Y. Li, Q. K. Cui, Catal. Commun., 2015, 61, 67-71.

[179] Q. J. Zhu, J. N. Kondo, T. Tatsumi, S. Inagaki, R. Ohnuma, Y. Kubota, Y. Shimodaira, H. Kobayashi, K. Domen, J. Phys. Chem. C, 2007, 111, 5409-5415.

[180] S. Hu, Y. J. Gong, Q. Zhang, J. L. Zhang, Y. F. Zhang, F. Y. Yang, T. Dou, CIESC J., 2012, 63, 3889-3896.

\title{
甲醇制丙烯：最重要的催化剂及其性能
}

\author{
M. Khanmohammadi ${ }^{\text {a, }}$, Sh. Amani ${ }^{\text {a }}$, A. Bagheri Garmarudi ${ }^{\text {a }}$, A. Niaei ${ }^{\text {b }}$ \\ a霍梅尼国际大学科学学院化学系, 加兹温, 伊朗 \\ ${ }^{\mathrm{b}}$ 大不里士大学化工与应用化学系, 大不里 $\pm 51666-16471$, 伊朗
}

摘要: 由于世界范围内原油缺乏和丙烯需求量增长, 在甲醇转化制烃类的不同路线中, 甲醇制丙烯(MTP)过程得到发展. 本文讨论了催化剂结构对MTP工艺条件的影响以及分子篎酸性、晶粒尺寸、中孔特性和拓扑结构等因素对催化剂催化MTP 反应活性和选择性的影响.

关键词: 甲醇制丙烯; ZSM-5分子筛; 催化

收稿日期: 2015-10-05. 接受日期: 2015-12-16. 出版日期: 2016-03-05.

*通讯联系人. 电话/传真: +98-28-3378 0040; 电子信箱: m.khanmohammadi@sci.ikiu.ac.ir

本文的英文电子版由Elsevier出版社在ScienceDirect上出版(http://www.sciencedirect.com/science/journal/18722067). 